\title{
A NEW DEVICE FOR STEREOTACTIC CT-GUIDED BIOPSY OF THE CANINE BRAIN: DESIGN, CONSTRUCTION, AND NEEDLE PLACEMENT ACCURACY
}

\author{
By \\ Alain Giroux, DVM \\ Master of Science \\ In \\ Veterinary Medicine \\ Jeryl Jones, Chair \\ Jan Helge Bøhn \\ Don Waldron \\ Robert Duncan \\ Karen Inzana
}

Thesis submitted to the Faculty of the Virginia Polytechnic Institute and State University in partial fulfillment of the requirements for the degree of

May, 2000

Blacksburg, Virginia

Keywords: Computed Tomography, CT, Stereotactic Biopsy, Canine, Dog, Brain, Interventional Radiology

Copyright 2000, Alain Giroux 


\title{
ACCURACY OF A NEW DEVICE FOR STEREOTACTIC CT-GUIDED BIOPSY OF THE CANINE BRAIN
}

\author{
Alain Giroux, DVM \\ Jeryl Jones, DVM, PhD, chair \\ Department of Radiology
}

\begin{abstract}
Computed tomography (CT) is an imaging technique that uses $\mathrm{x}$-ray and computers to create cross-sectional images of structures. Stereotactic CT-guided biopsy is defined as the use of a stable apparatus to direct and perform tissue biopsies under CT guidance. For the brain, the principal advantage of stereotactic $\mathrm{CT}$ guidance over other biopsy techniques is its high accuracy in getting a sample from deep-seated lesions. The objectives of this study were to create an inexpensive CT-guided stereotactic device adaptable to different canine head sizes and to test the accuracy of the device for needle placement in deep-seated brain targets. A biopsy device was created that consists of four main components: a CT table fixation device, a head fixture, a needle fixture, and motion control system. Accuracy was tested using 16 head and neck specimens obtained from dogs euthanitized for reasons unrelated to the brain. Deep-seated (caudate nucleus and pituitary gland) targets were identified on CT. After a $5 \mathrm{~mm}$ craniotomy, the biopsy needle, with CT monitoring, was progressively introduced into the target. The final needle track distance was measured on CT. The brain was removed and sliced to verify placement of the needle tip within the target and to measure the actual needle track distance. The total cost of materials and construction for the stereotactic CT-guided biopsy device was $\$ 785.00$. No difference in needle placement accuracy was identified for caudate and pituitary targets. Based on assessments by 2 independent observers, the caudate target was successfully hit $75 \%$ of the time. Pituitary targets were successfully hit $96.8 \%$ of the time. Actual needle track lengths were an average of $3.2 \mathrm{~mm}$ less that the track length measured on CT. This difference was most likely due to incomplete staining of the bevel part of the needle track on gross specimens.
\end{abstract}


Our new device shows similar accurate needle placement in brain targets of different depths. This device shows promise as an alternative to more expensive medical devices currently available for CT-guided stereotactic brain biopsy. Future studies are needed to test its accuracy in vivo.

This work was funded by the Pet Memorial fund, from the Virginia Veterinary Medical Association. Financial support was also provided by the VA-MD Regional College of Veterinary Medicine. 


\section{DEDICATION}

I would like to dedicate this thesis to my wonderful wife for her unconditional love, support and understanding, and for the wonderful gift of my daughter Madeleine.

I love you so much, Alain. 


\section{ACKNOWLEDGMENTS}

This research project and thesis benefited from extensive contributions of some wonderful people. Particularly, I would like to thank:

-Dr. Jeryl Jones, my research advisor, for her multiple encouragements, for all the weekends assistance and availability, for the uncountable scientific and organizational input that promoted tremendously the start, continuation and completion of this thesis.

-Dr. Jan Helge BØhn, committee member and associate professor in the mechanical engineering department, for providing great help, and for his invaluable time and ideas during the designing and testing phases of the device.

-Dr. Robert Duncan, committee member and professor in the pathology department, for teaching me how to extract and process the brain specimens, and for his important help in the development of a technique to identify and acquire the data on the specimens.

-Dr. Don Waldron, committee member and professor in the surgery department, for introducing me to several surgical instruments and surgical techniques.

-Dr. Karen Inzana, committee member and professor in the neurology department, for her practical input on cerebral structure identification, and on the brain biopsy technique.

-Pam Arnold, anatomical preparation coordinator, for her patience, assistance and ideas on instrumentation and techniques for specimen preparation.

-Susie Ayers, chief technologist of the radiology department, for instructing me on how to use the CT scanner, and for her assistance in scanning.

-Dan Ward, for his assistance in understanding and processing our statistics. Thank you all so much, Alain. 


\section{TABLE OF CONTENTS}

CHAPTER 1 REVIEW OF CANINE BRAIN BIOPSY TECHNIQUES

1.1 DEFINITION OF TERMS---

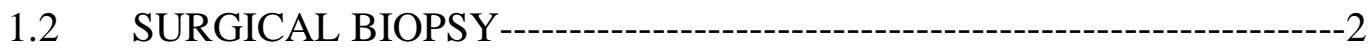

1.3 ULTRASOUND-GUIDED BIOPSY-----

1.4 CT-GUIDED AND STEREOTACTIC BRAIN BIOPSY-----------------4

1.5 CT-GUIDED AND STEREOTACTIC BRAIN BIOPSY TECHNIQUES

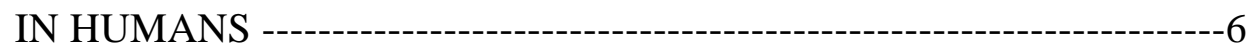

CHAPTER 2 DESIGN AND CONSTRUCTION OF A NEW STEREOTACTIC DEVICE FOR CT-GUIDED BIOPSY OF THE CANINE BRAIN------12

$2.1 \quad$ INTRODUCTION--

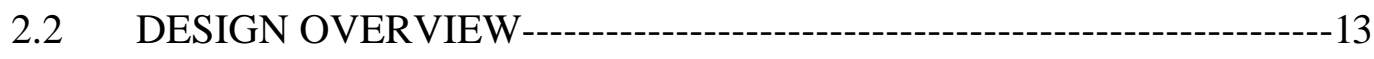

$2.3 \quad$ RESULTS --

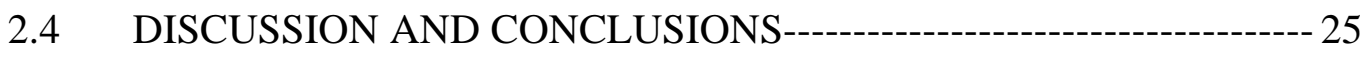


CHAPTER 3 ACCURACY OF A NEW STEREOTACTIC DEVICE FOR CTGUIDED BIOPSY OF THE CANINE BRAIN------------------------27

3.1 INTRODUCTION ------

3.2 METHODS AND MATERIALS -------------------------------------28

$3.3 \quad$ RESULTS ---

3.4 DISCUSSION---

THESIS CONCLUSION---

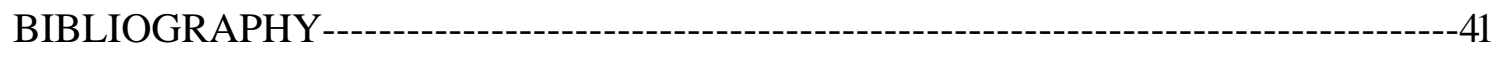

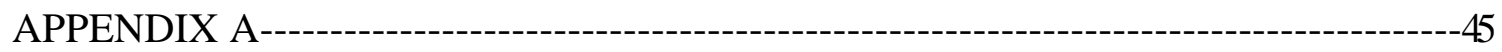

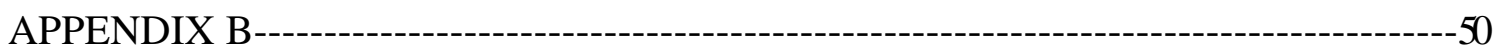

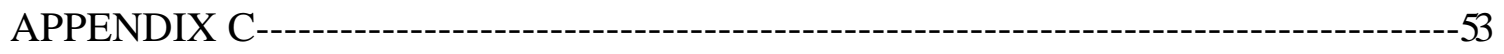

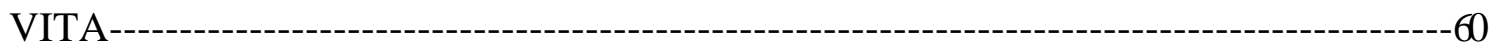




\section{TABLES AND FIGURES}

\section{Chapter 2}

Table 2-1 Requirements of a low-cost stereotactic CT-guided brain biopsy device for use in dogs-----------------------------------15

Figure 2-1 The major components of the new low-cost stereotactic CT-guided brain biopsy device for use in dogs ------------------------------------------14

Figure 2-2

Figure 2-3

Figure 2-4

Figure 2-5

Figure 2-6

Figure 2-7

Figure 2-8

\section{Chapter 3}

Figure 3-1 CT images demonstrating optimal angle of approach and pituitary target

Figure 3-2

Figure 3-3

Figure 3-4

Figure 3-5

Figure 3-6 identification

CT distance measurement before needle placement ------------------------37

CT distance measurement after needle placement---------------------------38 Actual needle track and confirmation of a successful pituitary hit ------38 Comparison of CT length versus actual length of needle track for caudate nucleus target -------------------------------------------------------40

Comparison of CT length versus actual length of needle track for pituitary target----------------------------------------------------------------------41 


\section{CHAPTER 1}

\section{REVIEW OF BRAIN BIOPSY TECHNIQUES}

\section{DEFINITION OF TERMS}

Computed tomography (CT) is the term used to describe the computer reconstruction and recording of internal body images at a predetermined plane by means of the tomograph; called also body section roentgenography. ${ }^{1}$ Biopsy is defined as the removal and examination, usually microscopic, of tissue from the living body, performed to establish a precise diagnosis. 1

There is some disagreement in the literature regarding the definition of deepseated brain locations. Thomas et al included the cingulate gyrus as a deep-seated region of the brain. ${ }^{2}$ Wen et al defined "deep-seated" lesions as those including the basal ganglia, the thalamus, and the posterior fossa but excluding the cingulate gyrus. ${ }^{3}$ For this thesis, the author will use this latter definition for "deep-seated" lesions.

"CT-guided biopsy" includes free-hand biopsies and any brain biopsies performed

under CT-monitoring for needle insertion with or without a needle guide. 4 These biopsies exclude techniques or case series in which CT data are translated into stereotactic coordinates for biopsy, or where lesions are aspirated in a stereotactic frame solely by reference to the coordinates. Stereotactic biopsy, employs CT coordinates and a head frame to guide needle placement. 


\section{SURGICAL BIOPSY}

The first published description of surgical brain biopsy in dogs was by Swaim et. al. in $1979.5^{5}$ At that time, very little had been written on surgical brain biopsy techniques. In this study, Swaim describes surgical techniques to obtain cerebral and cerebellar biopsies from two groups of 12 normal dogs. The surgical biopsy approach was from the lateral aspect with an incison made halfway between the lateral canthus of the eye and the rostral border of the base of the ear. The incision was carried through the temporal muscle down to the skull. Craniotomy was performed with either a pneumatic surgery instrument or a manual trephine. No clinical neurologic abnormalities were noted in any of the dogs from which cerebral biopsies were obtained. Two of the dogs from which cerebellar biopsies were taken exhibited temporary clinical signs of cerebellar dysfunction. Since then, the gold standard for diagnosing and treating canine brain mass lesions has remained excision and surgical biopsy. ${ }^{6-8}$ In 1990 , neurosurgical intervention for complete excision or cytoreduction before therapy, was considered essential in the management of intracranial tumors. 6 However, precautions in the approach of surgical biopsy were suggested because of the possibility of tumor seeding. Seeding, or spread of the tumor along the surgical margins is possible through cerebrospinal fluid transport and through neoplastic tissue manipulation. ${ }^{6}$ Also, other publications have suggested, without supporting data, that surgical brain biopsy is associated with a high morbidity rate. 8,9

Recently, a lower rate of morbidity for pituitary gland excisional biopsy has been described. 10 This study evaluated the results and complications of microsurgical trans- 
sphenoidal hypophysectomy performed on 52 dogs. Treatment failures included procedure-related mortalities (five dogs) and incomplete hypophysectomies (four dogs). The 1-year estimated survival rate was $84 \%$ (95\% confidence interval [CI], $71 \%$ to $92 \%$ ) and the 2-year estimated survival rate was $80 \%$ (95\% CI, $65 \%$ to $90 \%$ ).

\section{ULTRASOUND-GUIDED BIOPSY}

The use of ultrasound to direct canine brain biopsy was described in veterinary medicine by Thomas et. al. in $1993 .^{2}$ In this study using ten normal dogs, ultrasoundguidance was used to sample the right cingulate gyrus of 5 dogs and the right caudate nucleus of 5 others. A custom-made biopsy guide was fitted to a 7.5-MHZ intraoperative sector scanner probe, and a custom-made fixation apparatus was used to stabilize the probe during insertion of the a 16-gauge biopsy needle through a 12-mm craniotomy opening. Postoperative evaluation revealed no neurologic abnormalities during the first 14 days. Transient upper eyelid swelling, subcutaneous seroma and mild signs of pain were observed at the surgical site. It was concluded that the technique was accurate and safe to obtain brain tissue specimens from deep-seated lesions in this regard. However, there is some question whether the caudate nucleus constitutes a deep-seated lesion in this regard. The accuracy of biopsy needle placement, confirmed on post-mortem examination, was 9 hits out of 10 .

\section{CT-GUIDED AND STEREOTACTIC BRAIN BIOPSY}

The first report of CT-guided canine brain biopsy was published in 1982.11 In this technical report, the head of a beagle was placed inside a plastic cube and held 
securely by a horizontal bar under the upper jaw, a vertical screw, and two ear pins. The plastic cube contained a grid of burr holes in a vertical and horizontal plane. Although no biopsy procedure was described in this article, this simple device had an intended purpose of stereotactic orientation for biopsy or implantation of brachytherapy devices. Another report described the use of a stereotactic device to obtain brain biopsies in research dogs. However, the procedure and the results were not provided. ${ }^{12}$

Harari et. al. published a report in 1993 on free-hand CT-guided biopsy of brain tumors in 8 dogs. 13 A 13-gauge Field-Lee brain biopsy needle was inserted through a $5 / 16$ inch $(8 \mathrm{~mm})$ skull opening. In 3 out of 8 dogs a biopsy diagnosis of neoplasia was obtained. In the other 5 dogs, the tissues from the needle biopsy were normal. Follow-up necropsy diagnosis was obtained and confirmed the presence of brain neoplasm in all 8 cases. The diagnostic yield for this procedure was thus only 37\%. According to the authors, possible reasons for the poor success rate were: possible misinterpretation of contrast-enhanced CT images, movement of the biopsy needle after imaging and before sampling, technical errors in using the biopsy needle, presence of normal cellular foci within the tumor, easier aspiration of normal peritumor cells than of neoplastic cells, inadequate sample size, and inexperience in evaluating needle biopsy samples of brain tissue.

An abstract of a presentation describing successful use of a prototype device to perform CT-guided stereotactic biopsies in 2 dogs with brain tumors has been recently published. ${ }^{14}$ No description of the device or accuracy results were provided. 
Most recently, Koblik et. al. published 2 articles on CT-guided stereotactic brain biopsies performed with a modified Pelorus Mark III Stereotactic System. ${ }^{15,16}$ In the first article, the authors describe the CT-guided brain biopsy procedure. 16 This device utilized a $5 \mathrm{~cm}$ diameter aluminum and Plexiglas ${ }^{\mathrm{a}}$ skull ring that was secured to the skull by two cancellous bone screws and corresponding drilled holes. A $3 \mathrm{~mm}$ craniotomy was made through the skull ring with the help of a drill guide and drill bit. An 18-gauge spinal needle was used to create the dura mater opening. A side-cutting aspirator biopsy needle was advanced to a prescribed depth. In the second article, the authors describe the results of CT-guided stereotactic brain biopsies performed on 50 consecutive dogs using the modified Pelorus Mark III Stereotactic System. ${ }^{15}$ No apparent complications were seen in thirty-six dogs. In 5 dogs, postoperative clinical complications included transient epistaxis (1 dog), transient exacerbation of cerebellar signs ( $1 \mathrm{dog})$, obtundation progressing to coma ( $1 \mathrm{dog}$ ), and medically uncontrollable seizures ( $2 \mathrm{dogs})$. Three other dogs with large primary brain tumors had severe neurologic complications. The final diagnosis from surgical excisional histopathology and necropsy was in agreement with the stereotactic biopsy diagnosis in 20 of these 22 dogs. The authors concluded that this CT-guided biopsy procedure provided an accurate pathologic diagnosis of brain lesions detected by CT and MR neuroimaging, but further refinement of the technique was necessary to reduce the rate of clinical complications and to improve the accuracy of the procedure.

\footnotetext{
${ }^{\text {a }}$ Rohm and Haas Company Corporation, Delaware Independence Mall, West Philadelphia, Pennsylvania.
} 


\section{CT-GUIDED AND STEREOTACTIC BRAIN BIOPSY TECHNIQUES IN}

\section{HUMANS}

Reports on CT-guided brain biopsy in humans were first published in the 1970s and became even more numerous in the early 1980s.4,17-23 These early studies described CT protocols adapted for biopsy procedures, methods of needle insertion, and biopsy instrumentation for tissue diagnosis. Most involved performing a craniotomy using a twist drill or burr hole. Biopsy needles included the Cone biopsy needle, a side aspiration metal biopsy needle, angiocath needle, and Lee tissue biopsy needle. In some instances the needle was directed and held by hand (free-hand technique) or by using a needle guide. At that time, CT-guided biopsy techniques were reserved for patients who, in the judgment of the neurosurgeons, could not undergo significant resection of the tumor because of its location or because of significant involvement of the dominant hemisphere. ${ }^{20}$ In these situations, definitive diagnosis by CT-guided biopsy permitted better prognostic assessment and aided decisions about therapy. It was concluded by one of these reports that CT-guided needle biopsy was an accurate, relatively safe, and low cost method of brain lesions diagnosis. ${ }^{18}$ However, the locations of the lesions biopsied were mainly superficial, with most involving the cerebral hemispheres and few involving the basal ganglia.

Stereotactic CT-guided brain biopsy was increasingly utilized in the early 1980s. The most widely reported devices included the Riechert-Mundinger, Brown-RobertsWells, and Leskell units. ${ }^{24-26}$ All these instruments combined CT-scanning with a 
device fixed to the head in order to establish a geometric relationship between the external frame and the intracranial target. In addition,these instruments all possessed a guidance system for needle stabilization and insertion. 27 The Riechert-Mundinger instrument consisted of a stereotactic base head ring that was fixed by means of a fixer apparatus on the CT-table. ${ }^{28}$ This apparatus was vertically and horizontally adjustable with vernier micrometer screws. Cartesian target point coordinates of the stereotactic device were identical to the coordinates of the CT scanner when the 0-point of the stereotaxic device was in the origin of the CT scanner. The Brown-Roberts-Wells device consisted of a base ring, which was secured to the calvarium by carbon fiber posts and nylon-steel set pins for negligible artifact production on the CT scanner. ${ }^{29}$ A localizer unit, interfaced with a base ring, allowed the production of extracranial reference points that could be spatially related to the intracranial targets. An arc-shaped needle guidance system, which was exchanged for the localizer unit at the completion of scanning, allowed multiple angle settings for appropriate trajectories to target points. The Leskell system consisted of a semicircular arc mounted on a coordinate head base. ${ }^{30}$ The coordinates for the head base contained $\mathrm{X}, \mathrm{Y}$, and $\mathrm{Z}$ data that directed the biopsy using the CT computer $\mathrm{X}, \mathrm{Y}$, and $\mathrm{Z}$ target coordinates.

There is some controversy concerning which brain biopsy technique is superior. $3,4,29,31-36$ The users of CT-guided biopsy suggest that there is no difference in accuracy or that the small difference in accuracy reported does not justify the expense of stereotactic biopsy. $3,4,31,34$ The stereotactic developers maintain that the accuracy of 
the stereotactic device surpassed CT-guided biopsy alone and this is even more accentuated for deep-seated biopsy. $18,27,29,35,36$ A reported strength of CT stereotactic over the freehand biopsy technique is more precise needle placement. ${ }^{37}$ Stereotactic biopsy has been reported to be accurate within $1 \mathrm{~mm} \cdot{ }^{29,38}$ Free-hand biopsy has usually been limited to lesions greater than $1 \mathrm{~cm}$ in diameter. Deep central lesions requiring a long trajectory are considered to be more appropriately approached by means of the stereotactic method. ${ }^{37}$ Since similar biopsy needles are used in both procedures, no advantage in sample size has been obtained with either freehand or stereotactic biopsy. An important study that compared ultrasound-guided biopsy and stereotactic brain biopsy was published in 1991.32 The study consisted of 41 patients undergoing intracranial lesion biopsy. Eighteen biopsies were obtained using CT-guided stereotactic procedures and 23 using ultrasound guidance. In this study, all posterior cranial fossa lesions were biopsied with the CT-guided stereotactic technique. The study resulted in a diagnostic yield of $94 \%$ and $91 \%$ for CT-guided procedures and ultrasound-guided procedures, respectively. The authors concluded that although ultrasound-guided biopsy has been reported to be suitable for lesions larger than $5 \mathrm{~mm}$ in diameter, they preferred to use it only for lesions over $15 \mathrm{~mm}$. They also concluded that the advantage of the CT technique was its high accuracy; whereas the ultrasound-guided procedure was simpler, quicker, and more economical to perform.

An article comparing CT-guided and stereotactic biopsies was published in 1987 by Goldstein. ${ }^{31}$ Sixty-four CT-guided free-hand biopsies and thirteen stereotactic 
biopsies with the Brown-Roberts-Wells device were performed on superficial and deep brain lesions. No significant differences concerning diagnostic yield, morbidity and mortality were seen between the two techniques. The conclusion of this study was that CT-guided free-hand biopsy was a safe and effective way to obtain brain-tissue specimens for histological diagnosis. It was less costly and less time-consuming than stereotactic biopsy and yielded the correct diagnosis as often.

In another study, Greenblatt et. al. concluded that for small, deep lesions located near the midline, stereotactic biopsy seemed to hold a slight edge over the CT-guided technique. ${ }^{37}$ However, there were analytical difficulties in making this comparison. The authors reported that the case success rate for stereotactic CT biopsy was in the range of 91 to $93 \%$, whereas the procedure success rate for CT-guided biopsy was about $85 \%$. But the CT-guided procedures included a majority of more superficial lesions. Therefore, the reported success rate was biased by case selection criteria used for the two techniques.

In 1993, a large study was published comparing 75 CT-guided biopsies and 66 stereotactic biopsies. ${ }^{3}$ In this retrospective study, the medical and radiological records of all patients were reviewed to determine the size and site of the lesion, biopsy technique, pathological diagnosis, correlation of the diagnosis with subsequent open surgical procedures or autopsy findings, morbidity, and mortality. The authors excluded from analysis 14 of the stereotactic and 12 of the CT-guided biopsy samples obtained from deep lesions. The reason for exclusion was to eliminate the selection bias of some surgeons, who maintained that, in cases of very small and/or deep lesions, only stereotactic biopsy should be employed. The study concluded that there was no 
appreciable difference in the complication rates between freehand CT-guided and stereotactic biopsies for superficial brain lesions. A disappointing part of this study was the questionable exclusion of the biopsy of deep-seated lesions. If analysis had been performed on them, the authors could have more meaningfully compared the accuracy of the two techniques.

In 1995, Duquesnel et. al. performed CT-guided needle biopsies on 118 patients. A total of 134 procedures were done. ${ }^{34}$ A positive diagnosis of tumour was obtained in 106 patients $(89.8 \%)$. Repeat procedures were required in 18 patients. High-grade gliomas were the more common lesions (55.1\%). Morbidity and mortality was assessed over the 30-day period after the procedure. Nine patients died during this time: eight patients died during day 3 through day 30 in the expected course of their disease, and one died within the first 48 hours due to neurological deterioration following the procedure. The authors concluded that, for superficial and large lesions, CT-guided needle biopsy was a simple, fast and effective procedure. Also, the accuracy of stereotactic biopsy was considered to be important in the case of small lesions.

Krieger described stereotactic biopsy in his review article. He stated that "stereotactic biopsy has evolved as a powerful and safe tool to provide tissue diagnoses with minimal disruption of the normal-functioning brain". $39 \mathrm{He}$ also concluded that "it plays a significant role in the management of malignant brain tumors, where the benefit of open surgery might not justify the concomitant risks."

A recent published study reviewed two hundred twenty-five consecutive CTguided stereotactic brain biopsy procedures. 40 In this study, $61.3 \%$ of biopsied lesions 
were lobar (superficial); the remainding (38.7\%) were deep-seated (thalamus, basal ganglia, pineal, hypothalamus, cerebellum, brainstem). Demographical, anatomical, surgical, and histological data were compiled and putative risk factors for morbidity identified. Twelve patients suffered complications as a consequence of the biopsy procedure (eight from hemorrhage, four from direct trauma). Major morbidity (hemiparesis, aphasia, obtundation) occurred in eight patients (3.6\%). Three patients (1.3\%) suffered minor morbidity (transient, mild neurological deficits). One operative fatality occurred $(0.4 \%)$. In the author's opinion, image-guided stereotaxy was considered the more appropriate means to sample tissue from small or deeply seated intraparenchymal lesions with a relatively high degree of safety and accuracy. 


\section{CHAPTER 2}

\section{DESIGN AND CONSTRUCTION OF}

\section{A NEW STEREOTACTIC DEVICE FOR CT-GUIDED BIOPSY OF THE CANINE BRAIN}

\section{INTRODUCTION}

Brain mass lesions are a common problem in dogs. 41 Causes include primary neoplasia, metastatic neoplasia, inflammatory diseases, vascular abnormalities and parasitic diseases. With the advent of imaging techniques such as computed tomography (CT) and magnetic resonance imaging (MRI), such brain mass lesions are increasingly being diagnosed antemortem and treated. ${ }^{6}$ Tissue biopsy is needed for a definitive diagnosis, because neoplastic and non-neoplastic brain masses can have similar imaging characteristics. ${ }^{6}$ In humans, stereotactic CT-guided biopsy is considered to be the most accurate and least invasive method for obtaining a histological diagnosis, especially for deep-seated brain lesions. 40 At the time this study was initiated, no stereotactic biopsy device was available for use in dogs. Since then, a human stereotactic device was modified for canine brain biopsy. 15,16 The purpose of our study was to design and construct a new, inexpensive, non-invasive stereotactic device for CT-guided canine brain biopsy. 


\section{DESIGN OVERVIEW}

The design shown in Figure 2.1 is based on the design requirements for a low-cost stereotactic CT-guided brain biopsy device for use in dogs, which are given in Table 2.1, and a series of four pilot tests (Appendix A). The dog head is held in a fixture clamped about its maxilla. This fixture can be moved in the horizontal XY-plane and rotated about the B-axis, which is perpendicular to the vertical CT scan plane. The head fixture is attached to the XYB-motion assembly, which in turn is attached to a base plate that is attached to the CT scan table. The biopsy needle is guided vertically in the CT scan plane through a fixture located on a rig that is attached to the same base plate as the XYBmotion assembly. The entire CT table (and hence the stereotactic device) can be moved in and out of the CT scan plane, and the CT scan plane can be tilted sufficiently to match direction of the biopsy needle.

Preliminary design satisfying the requirements are shown in figures $2-2 \mathrm{a}, 2-2 \mathrm{~b}, 2-$ 2c. A cardboard model of all the device components was made to help determine the optimal device dimensions and its operation. Canine skulls were also used to estimate spatial dimensions. Candidate construction materials were scanned to determine whether they caused CT artifacts. These included Plexiglas ${ }^{\mathrm{b}}$, wood, nylon and stainless steel. Plexiglas and nylon screws were determined to be the materials of choice. Each component was made separately and adjusted as needed to integrate it with the other parts. When all the components were completed and assembled, the device was tested through four pilot studies and refined after each study (Appendix A). Formaline-fixed 
fresh frozen canine head and neck specimens were utilized as test samples and scanning was performed with a fourth generation $\mathrm{CT}$ scanner. ${ }^{\mathrm{c}}$

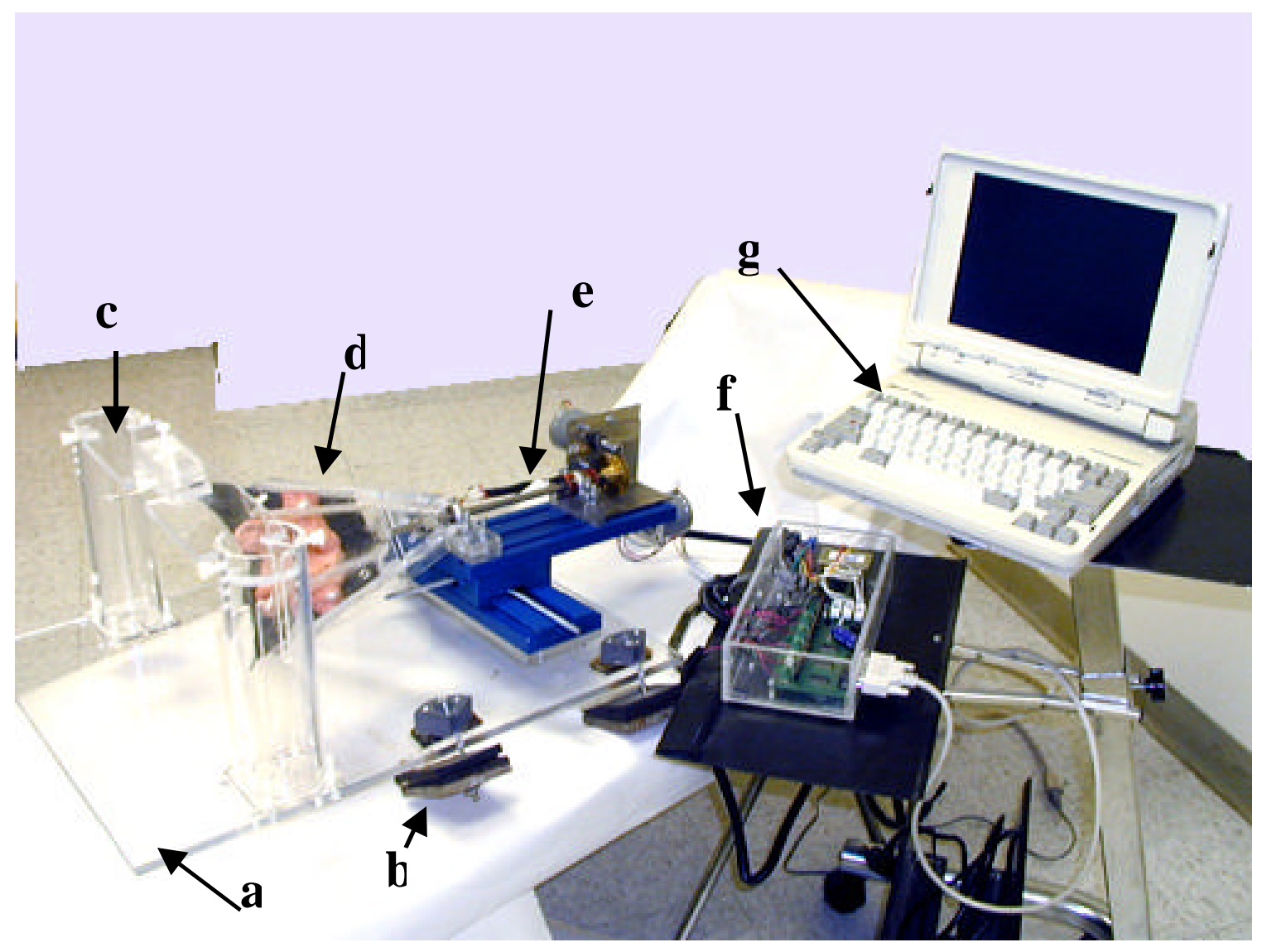

Figure 2-1. The major components of the new low-cost stereotactic CT-guided brain biopsy device for use in dogs. Indicated by corresponding letter: a) base plate; b) table clamps; c) needle fixture and rig; d) head fixture; e) XYB-motion assembly; f) motion control system; g) computer.

\footnotetext{
${ }^{\mathrm{b}}$ Rohm and Haas Company Corporation, Delaware Independence Mall, West Philadelphia, Pennsylvania. ${ }^{\mathrm{c}} \mathrm{IQ} / \mathrm{T}$, Picker International, Cleveland, Ohio.
} 
Table 2-1. Design requirements for a low-cost stereotactic CT-guided biopsy device for use in dogs.

- $\quad$ The device needs to be inexpensive.

- All components of the device that will be imaged on the CT scanner have to be made of material that will not cause artifacts.

- $\quad$ The CT table fixation device (platform) needs to be adaptable to different CT tables without requiring changes in the $\mathrm{CT}$ table.

- $\quad$ The head fixture (HF) has to provide a high degree of stability without any invasive components.

- $\quad$ The HF has to be adaptable to different dog head sizes and conformations.

- The motion control system (MCS) must be able to position the HF with a tolerance of 0.010 inches $(0.25 \mathrm{~mm})$.

- $\quad$ The MCS must be easy to control.

- $\quad$ The HF and MCS must be able to manipulate a weight between 8 to 40 pounds (3.6 to $18 \mathrm{~kg}$ )[the estimated weight of the head and neck of the patient].

- The needle fixture (NF) material has to maintain the needle in a single plane during advancement.

- $\quad$ The NF material needs to be gas sterilizable.

- $\quad$ The NF rig needs to be height-adjustable for different head sizes and needle lengths.

- $\quad$ The NF needs to be removable to permit craniotomy. 


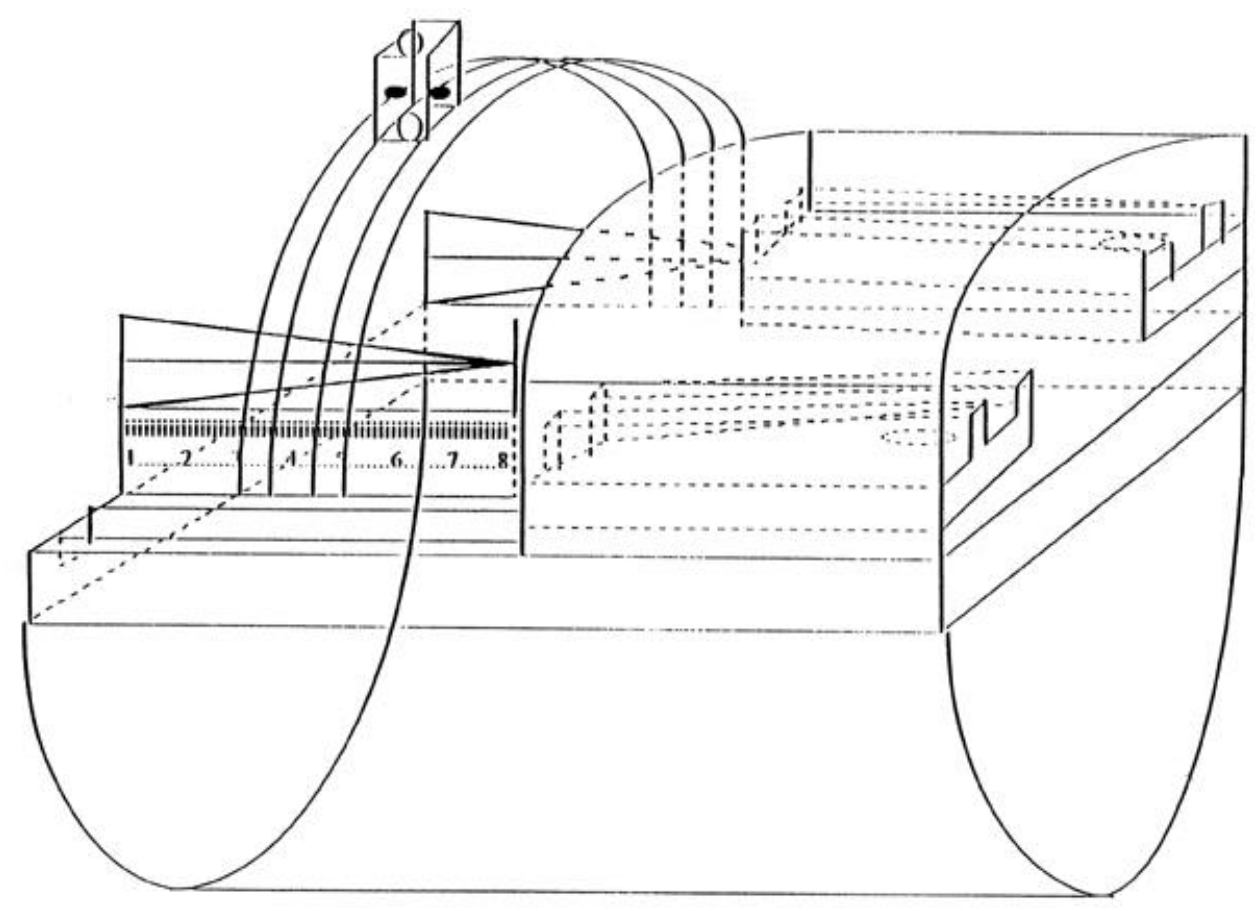

Figure 2-2a. Preliminary design sketch, isometric view.

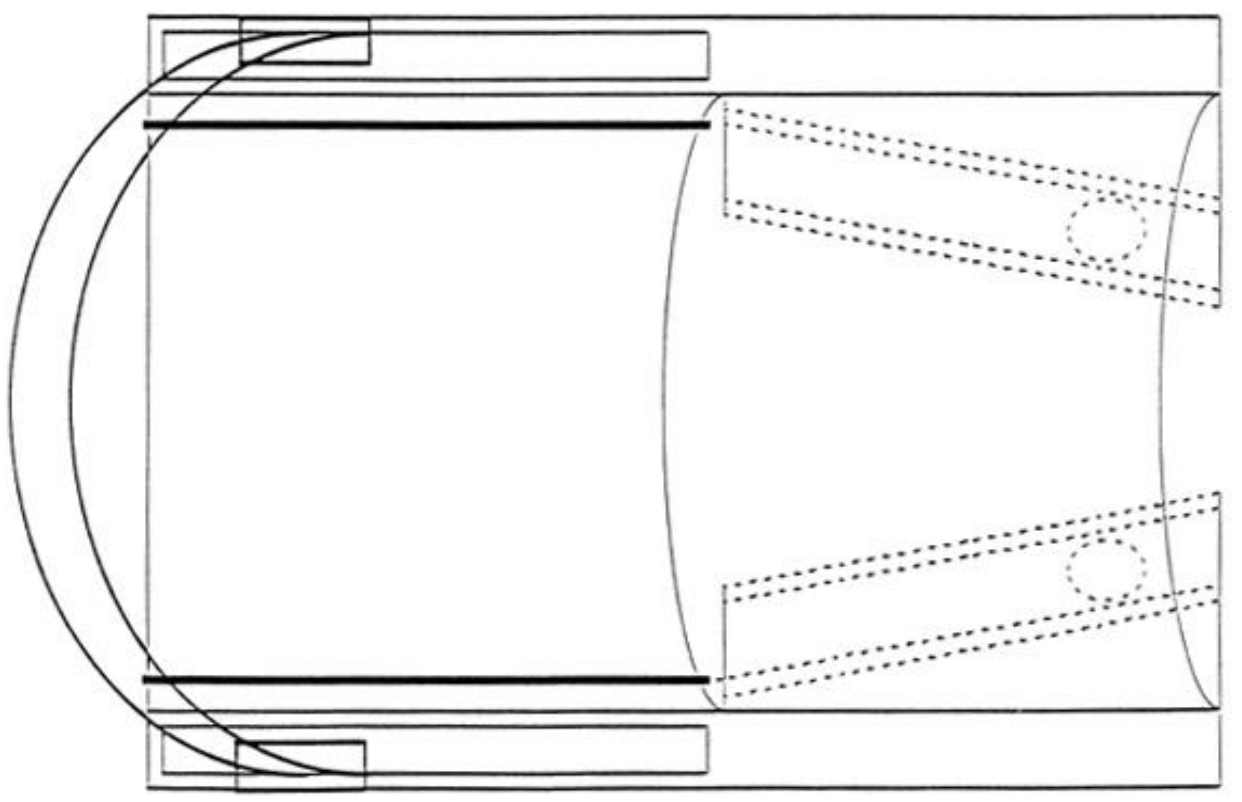

Figure 2-2b. Preliminary design sketch, the top view. 


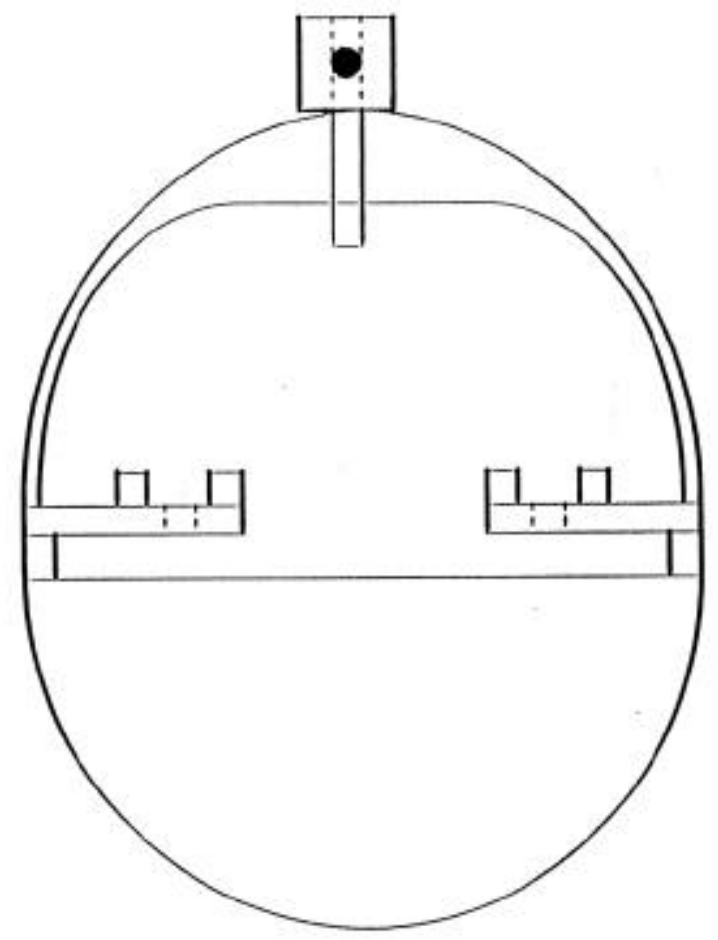

Figure 2-2c. Preliminary design sketch, front view.

\section{$\underline{\text { RESULTS }}$}

The result is a stereotactic device for CT-guided brain biopsy for use in dogs that costs $\$ 785$ in materials and supplies (labor has been excluded). The bill of materials is shown in Appendix B. The following sections will describe the main components of the device in more detail.

\section{Platform}

The entire stereotactic device needs to rest on, and be temporarily attached to, the CT table. Therefore, to facilitate assembly and disassembly, the various stereotactic device components are attached to a 5/16 inch $(7.9 \mathrm{~mm})$ Plexiglas base plate measuring 24 by 18 
inches ( 60.96 by $45.72 \mathrm{~cm})$. This base plate is in turn attached by four clamps to the CT table. These clamps consist of a $1 / 4$ inch $(6.4 \mathrm{~mm})$ Plexiglas plate that is pulled to the base plate by a screw that is tilted to match the shape of the CT table (Figure 2.3). These plates are lined with closed cell foam pads to improve the grip onto the CT table and to reduce the likelihood of scratching the $\mathrm{CT}$ table surface. The base plate also contains a series of through holes for attaching the needle rig and the XYB-motion assembly. 

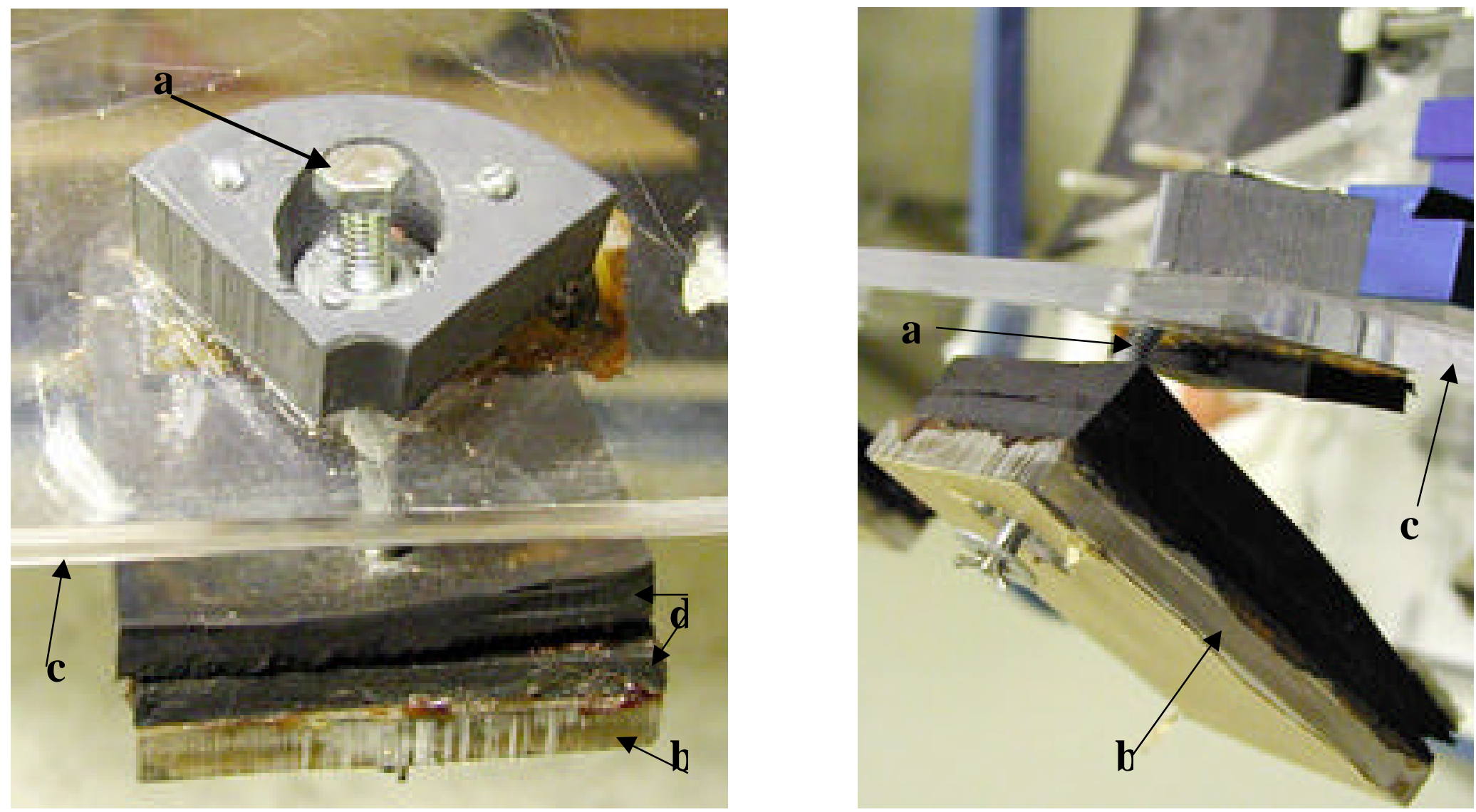

Figure 2-3. Top and side view of a CT table clamp. The tilted screw (a) pulls the small Plexiglas plate (b) and the base plate (c) together to match the shape of the CT table edge. The closed cell foam pads (d) enhance the grip onto the CT table and protects the surface of the CT table. 


\section{HEAD FIXTURE}

The head fixture has a triangular shape to conform to the general shape of the canine maxilla. The fixture consists of a 1/4 inch $(6.4 \mathrm{~mm})$ Plexiglas base plate that has been stiffened by two vertical Plexiglas walls (Figure 2.4). A Plexiglas sheet, which has been deformed under heat to match the general shape of canine maxillae and nasal bones, is pulled down onto this base plate via four nylon screws (Figures 2.4 and 2.5). The base plate and the curved sheet are each lined by a closed foam pad to enhance the grip about the maxilla and to prevent injury. In addition, a dental impression, custom made to each dog, is placed on top of the base plate foam pad for additional grip about the maxilla (Figures 2.5 and 2.6). This provides a firm grip about the maxilla, which is necessary when the head is rotated about the B-axis, which is along the steel rod to which the head fixture is attached. To minimize the torque generated by the head along the B-axis, the head fixture is balanced such that the head fixture's center of gravity is located along this axis (Figures 2.4 and 2.6).

The dental impressions were made using conventional dental impression material. ${ }^{d}$ The impressions were made on a portable base plate similar to the head fixture base plate that is permanently attached to the XYB motion assembly. In particular, the two base plates have screws in the same location (Figure 2.6). Hence, the impressions made on the portable base plate, with the dental material surrounding its screws, would fit onto the fixed base plate without them being able to move around during use.

${ }^{\mathrm{d}} 7312$ vinyl polysiloxane impression material putty, 3M ExpressTM STD, 3M Dental Products, St. Paul, Minnesota. 


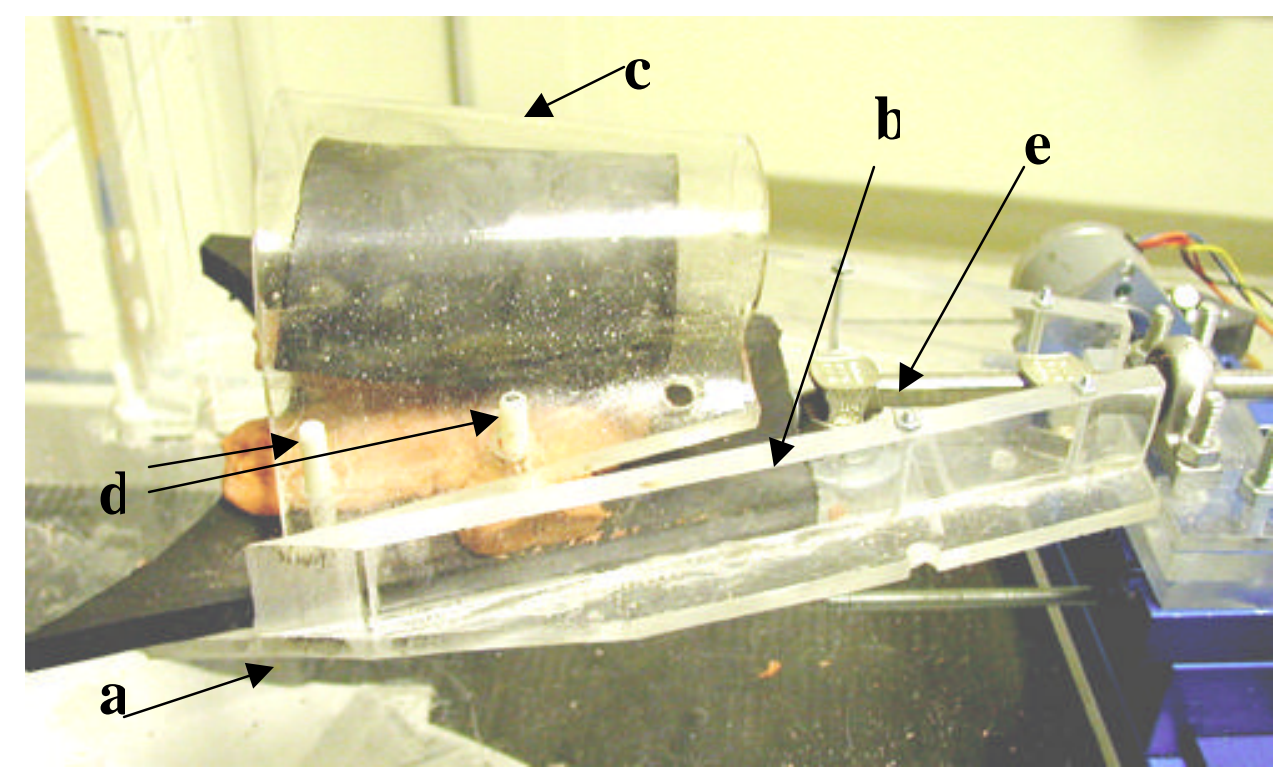

Figure 2-4. Side view of head fixture: a) base plate; b) vertical stiffening walls; c) curved sheet; d) nylon screws; e) rotating rod and its attachments.

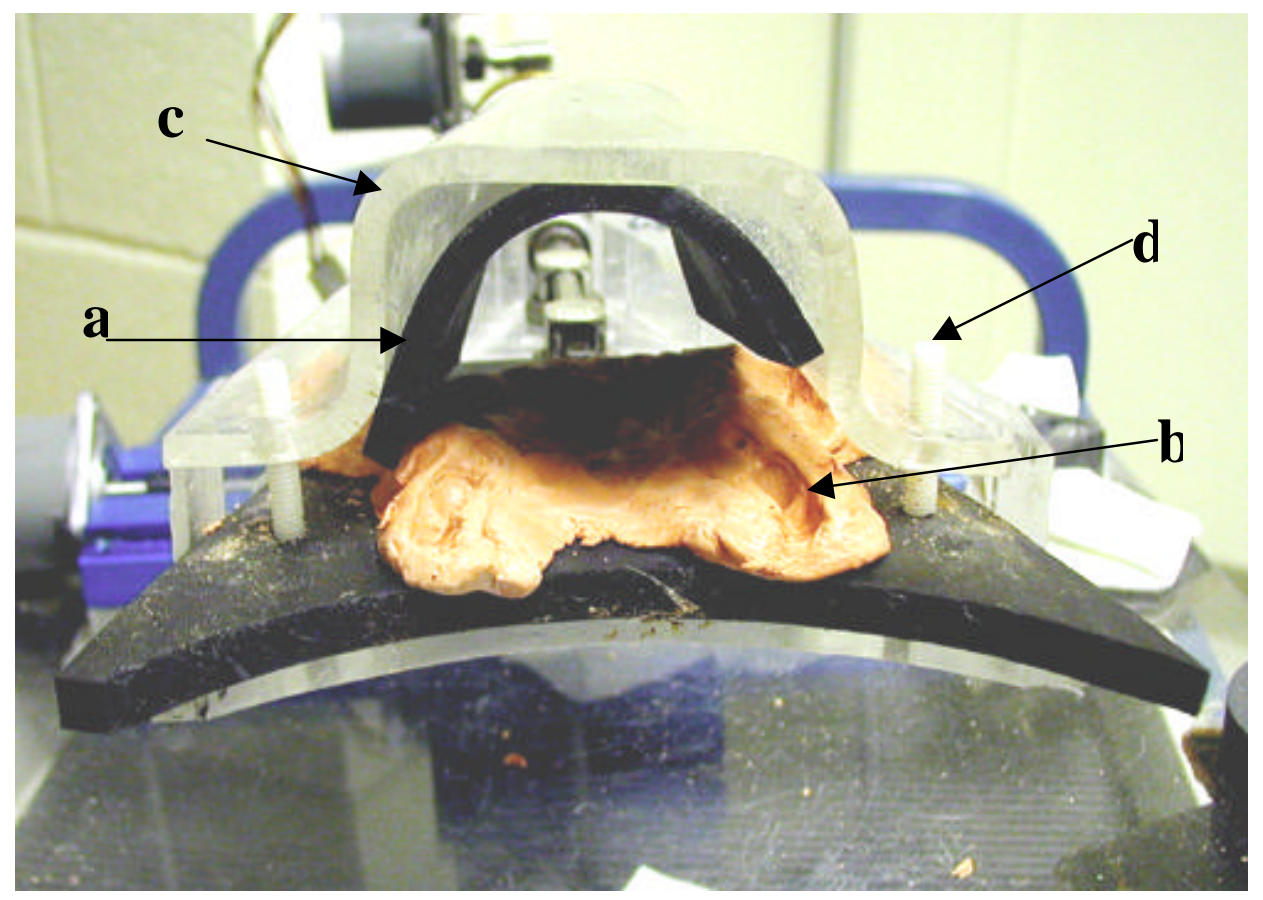

Figure 2-5. Back view of head fixture: a) foam pads; b) dental imprint; c) curved sheet; d) nylon screws. 


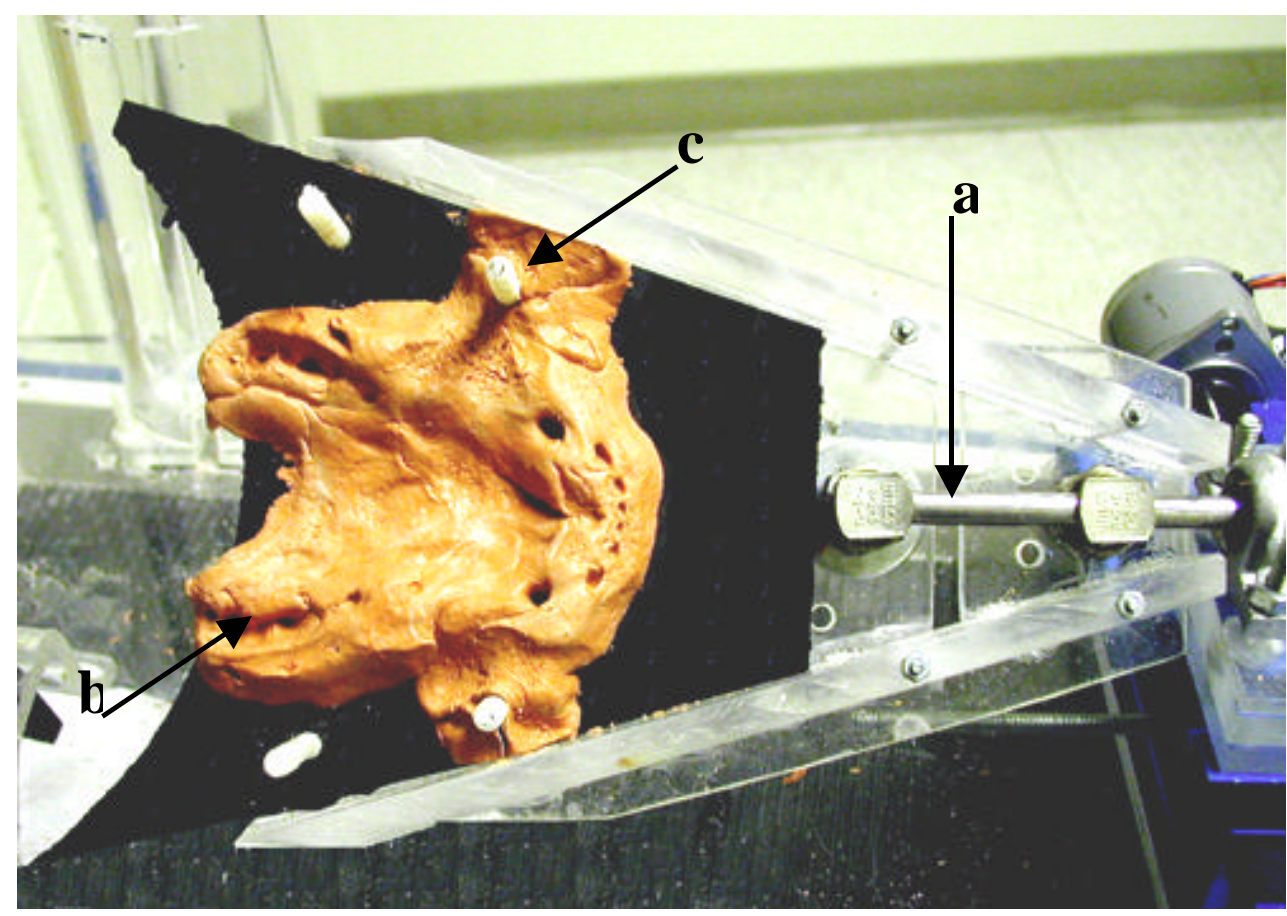

Figure 2-6. Top view of head fixture: a) rotating rod and its attachments; b) dental imprint; c) imprint material surrounding nylon screws.

\section{NEEDLE FIXTURE AND RIG}

The needle rig consists of two vertical Plexiglas round tubes $(9.1 \mathrm{inch} / 230 \mathrm{~mm}$ tall, $3 \mathrm{inch} / 76 \mathrm{~mm}$ outer diameter, $2.75 \mathrm{inch} / 70 \mathrm{~mm}$ inner diameter). Each tube is fitted with a square base so it can be attached to the stereoscopic device base plate using nylon screws, with one tube on each side of the head fixture (Figure 2.7). Each tube has a vertical slot to guide a horizontal $1 / 4$ inch $(6.4 \mathrm{~mm})$ Plexiglas plate as it slides up and down these tubes. This plate can be attached at a one of four fixed heights along these tubes using nylon screws. The needle fixture is mounted in the center of this horizontal plate, its center hole is lined with a Teflon tube, and it has a nylon screw that can lock the biopsy needle in place. 


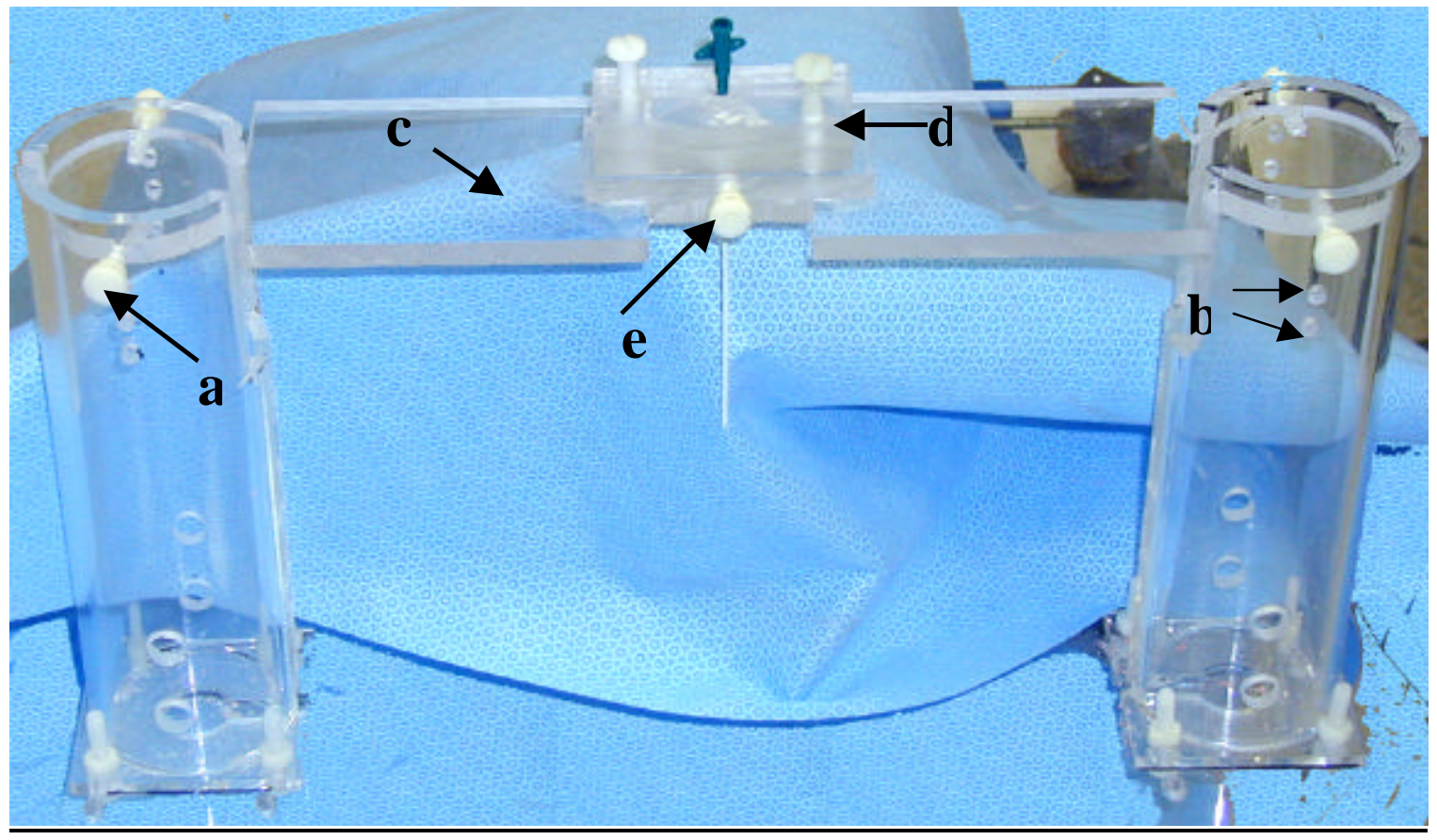

Figure 2-7. Needle rig tube, its center plate, and the needle fixture assembled with a biopsy needle in position: a) nylon screws on base; b) location of holes for attaching center plate; c) center plate; d) needle fixture; e) and needle lock screw. 


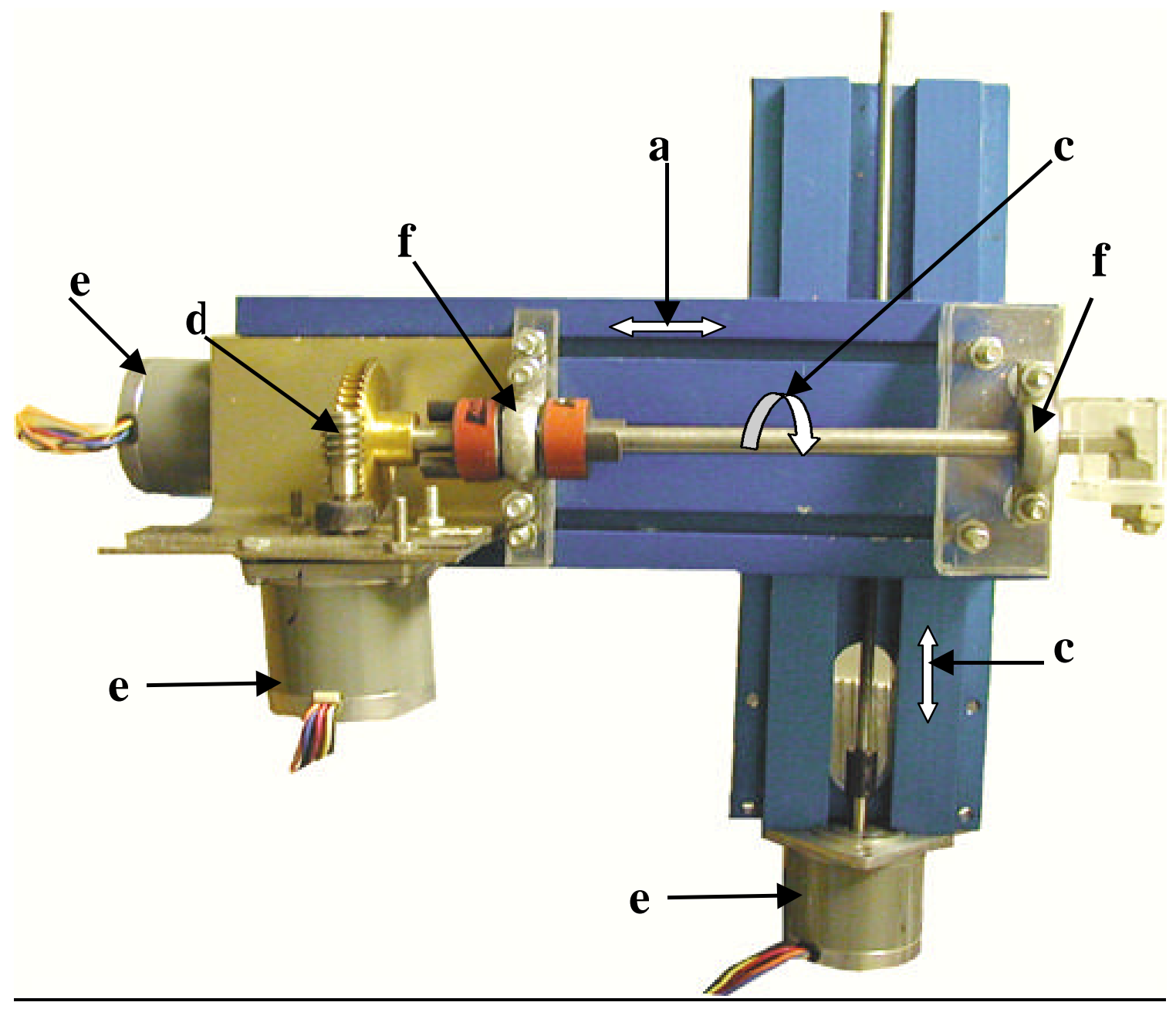

Figure 2-8. Top view of XYB-motion assembly: a) X-axis; b) B-axis; c)Y-axis; d) worm gear; e) stepping motors; f) two bearings.

\section{$\underline{\text { XYB-MOTION ASSEMBLY AND CONTROL SYSTEM }}$}

The XYB-motion assembly consists of one rotational and two linear stages (Figure 2.8). The rotational B-axis stage is connected to the head fixture via a steel rod resting on two bearings and attached to a 50:1 single thread worm gear that acts as a gear reducer. This gear reduction is necessary to increase the $70 \mathrm{oz} / \mathrm{in}(0.5 \mathrm{~N}-\mathrm{m})$ stepper motor holding power to $3500 \mathrm{oz} / \mathrm{in}(24.7 \mathrm{~N}-\mathrm{m})$ in order to manage the rotational torque imposed 
by the weight of most dogs. For instance, the increased holding power is sufficient for a $25 \mathrm{~kg}$ center of mass located up to $0.1 \mathrm{~m}$ to the side of the rotational axis. The rotational $\mathrm{B}$-axis stage is sits on top of the linear $\mathrm{X}$-axis stage, which in turn sits on top of the linear Y-axis stage. Each linear stages is driven by a 70 oz/in $(0.5 \mathrm{~N}-\mathrm{m})$ stepper motor attached directly to a standard 114"-20 threaded rod acting as a lead screw. The three stepper motors are powered by a 3-axis controller and its associated MS-DOS software via a standard parallel port. ${ }^{\mathrm{e}}$ The software and the controller is capable of executing standard G-code and operating all three axes simultaneously, though in our study the software was only used to manually jog one axis at a time from a laptop PC (Figure 2.1).

\section{DISCUSSION AND CONCLUSIONS}

When this study was initiated, there were no stereotactic devices available for canine brain biopsies. Devices designed for humans were considered inappropriate for use in dogs because the adult human head has a round shape whereas the canine skull is smaller and has an elongated oval shape when viewed from the axial plane. $24,25,28$ Furthermore, the devices used in human medicine employ burred holes into the skull bones or pin implantations, which is a method of stabilization that is made difficult by the massive maxillary and temporal muscles covering most of the canine skull surface.

After our study was initiated, Koblik et al. published a procedure modifying and using a human stereotactic device for canine brain biopsy. ${ }^{15,16}$ This device uses three

\footnotetext{
${ }^{\mathrm{e}}$ kit containing 3 motors, controller, transformer, and software; PIN 20120, MAXNC Inc., Chandler, Arizona.
} 
burred holes skull holes and cancellous bone screws for fixation onto the canine frontal bone. At a list price of $\$ 25,950$, this device may still be too expensive for many veterinary centers (the list prices human brain biopsy devices range from $\$ 20,000$ to $\$ 62,300$ ). The reason for this high cost is the materials used (aluminum alloys, titanium, and carbon fiber) and the precision manufacturing their components.

The new stereotactic CT-guided brain biopsy device presented here is noninvasive beyond the biopsy itself and costs about $\$ 785$ in materials and supplies. Its manufacture, including the cost of labor, should be less than $\$ 1,500$. this should give a list price of less than $\$ 5,000$ if made commercially available.

The new device has been evaluated in test studies using post-mortem specimens. These studies have provided suggestions for future refinements, and have provided evidence that thecurrent device can maintain sufficient stabilization of the canine head for accurate biopsy needle placement in the brain. 


\section{ACCURACY OF A NEW STEREOTACTIC DEVICE FOR CT-GUIDED BIOPSY OF \\ THE CANINE BRAIN}

\section{$\underline{\text { Introduction }}$}

An accurate histologic diagnosis is important for treatment planning in dogs with brain lesions. 31,33 Methods previously described for obtaining brain biopsies in dogs include surgical incision and excision, ultrasound-guided, free-hand CT-guided, and stereotactic CT-guided techniques. $2,5-8,10-16$ Stereotactic CT-guided brain biopsy is defined as a biopsy that employs CT coordinates and a head frame to perform needle placement. ${ }^{4}$ In humans, this technique has been described as the preferred method for obtaining biopsies of deep-seated brain lesions. $29,31,38$ We have recently designed and constructed a new device for stereotactic CT-guided biopsy of the canine brain. The purpose of this study is to evaluate the effects of target location on the accuracy of needle placement with this new device. 


\section{MATERIAL AND METHODS}

Sixteen canine head and neck specimens were collected from dogs scheduled to be euthanized for reasons unrelated to brain disease. Selected dogs were mostly of mesaticephalic conformation. Anesthetized dogs were injected with 1000 units/kg of heparin intravenously 10 minutes prior to pentobarbital euthanasia. The head and neck specimens were removed at the fifth-sixth cervical vertebrae. The vertebral canal was occluded with a hand-kneadable epoxy putty. ${ }^{\mathrm{f}}$ Both carotid arteries were canulated. A motorized pump was used with 3 pounds pressure per square inch to perfuse solutions into the carotid arteries. ${ }^{\mathrm{g}}$ Five liters of non-sterile saline were perfused to flush blood out of the specimen. Seven liters of $10 \%$ buffer formaline solution were perfused over 20 minutes. During perfusion of the last liter, both jugular veins, and the carotid and vertebral arteries were occluded with hemostatic clamps to reduce leakage of fixation solution out of the specimen. After perfusion, specimens were placed at room temperature for 90 minutes and then placed in a lidded plastic container. Specimens were stored in a 4 degree Celsius refrigerator until the time of data collection.

Immediately prior to the stereotactic needle placement procedure, $3 \mathrm{~cm}$ by $4 \mathrm{~cm}$ bilateral muscle and skin flaps were removed from the temporal region of the cranium. A maxillary dental impression was made for each dog using dental impression material placed in a mold identical in shape to the head holding fixture. ${ }^{\mathrm{h}}$ The stereotactic device was then positioned on the CT table and fixed in place. A 14 gauge, 6-inch biopsy needle

\footnotetext{
${ }^{\mathrm{f}}$ Aqua Nu-Doh, Drummond American Corporation, Vernon Hills, IL

${ }^{\mathrm{g}}$ Porti-bov perfusion pump.
} 
was placed in the needle fixture. ${ }^{\mathrm{i}}$ A CT slice localization study was acquired of the head and needle fixture. Four to six slice plane were posted at different gantry tilt angles. The angle that provided the best alignment between the CT-scanner plane and the needle was recorded and used for subsequent needle placement. Best alignment was based on maximum visualization of the needle lumen and tip. The true needle tip was identified based on an abrupt and distinct appearance on CT images. ${ }^{42}$ Transverse CT images of the brain and device were obtained using the following technique settings: Inner Ear Canal protocol, $2 \mathrm{~mm}$ slice thickness, $1 \mathrm{~mm}$ slice spacing, image size $180 \mathrm{~cm}, 240 \mathrm{~cm}$ field of view, prone orientation, $130 \mathrm{kVp}$ and 315 MAS. Caudate nucleus and pituitary gland targets were identified from the CT images for each dog. The target side of approach was randomized among dogs.

For each target, optimal angles of approach and distance measurements were recorded from images displayed on the CT monitor before the craniotomy (Fig. 3-1). Optimal angles of approach were chosen using the following criteria: head rotation no greater than 30 degrees, minimal surface to target distance, minimal involvement of the lateral ventricles. The head was rotated until the optimal approach angle was determined. Window and level settings were adjusted as needed to maximize visualization of the target and needle. The needle, already placed in the rig, was advanced to the external surface of the skull, and a felt tip marker was used to mark the desired site for craniotomy.

\footnotetext{
${ }^{\mathrm{h}} 7312$ Vinyl Polysiloxane Impression Material Putty, 3M Express ${ }^{\mathrm{TM}}$ STD, 3M dental Products, ST. Paul, $\mathrm{MN}$
} 
With the motion controllers, the head was moved out of the gantry and the craniotomy was created using an air drill and burr. ${ }^{\mathrm{j}}$ Then the head was repositioned at the same location and the needle was advanced to the brain surface. A distance measurement from the brain surface to the target was performed and recorded from the displayed CT image using electronic cursors (Fig. 3-2). A high precision caliper was used to mark the needle for the exact length of introduction into the brain. Transverse CT scans of the brain were repeated two times during needle placement to monitor the trajectory of the needle relative to the target. At one half the distance, the needle was rotated 180 degrees to correct for any angulation out of the desired path. When needle placement was complete, a distance measurement from the brain surface to the tip of the needle was made (Fig. 3-3). Then the metallic inner stylet was removed from the needle and $0.3 \mathrm{ml}$ of tissue staining solution was injected through the plastic sleeve of the catheter. ${ }^{k}$

After completion of the needle placement procedures, each specimen was returned in the refrigerator. Two to four weeks post-needle placement, the brains were removed from the cranial vault and placed in $10 \%$ formaline solution for 14 to 21 days. Brains were sliced gradually to identify each needle track. Additional blue stain was infused into the needle tracks as needed to improve visualization (Fig. 3-4).

Two evaluators independently identified the needle tracks for each target and recorded length measurements and success of hitting the targets. These assessments were performed without knowledge of the results of the CT stereotactic procedure or of the

\footnotetext{
${ }^{i} 14 \mathrm{Ga}$. Polyurethane IV catheter, Mila International, INC., Florence, KY.

${ }^{j}$ Surgairtome ${ }^{\circledR}$, Linvatec's, Hall ${ }^{\circledR}$ Surgical division, Largo, Fl.

${ }^{\mathrm{k}}$ Methylene Blue Counterstain, Shandon Inc, Pittsburgh, Pennsylvania, USA.
} 
other evaluator's assessment. The null hypothesis that the proportion of hits was the same for pituitary and caudate targets, was tested using a Fisher's Exact test. Statistical significance was set at $\mathrm{P}<0.05$. The $\mathrm{CT}$ needle track lengths were compared to the actual needle track lengths using a paired $\mathrm{T}$ test.

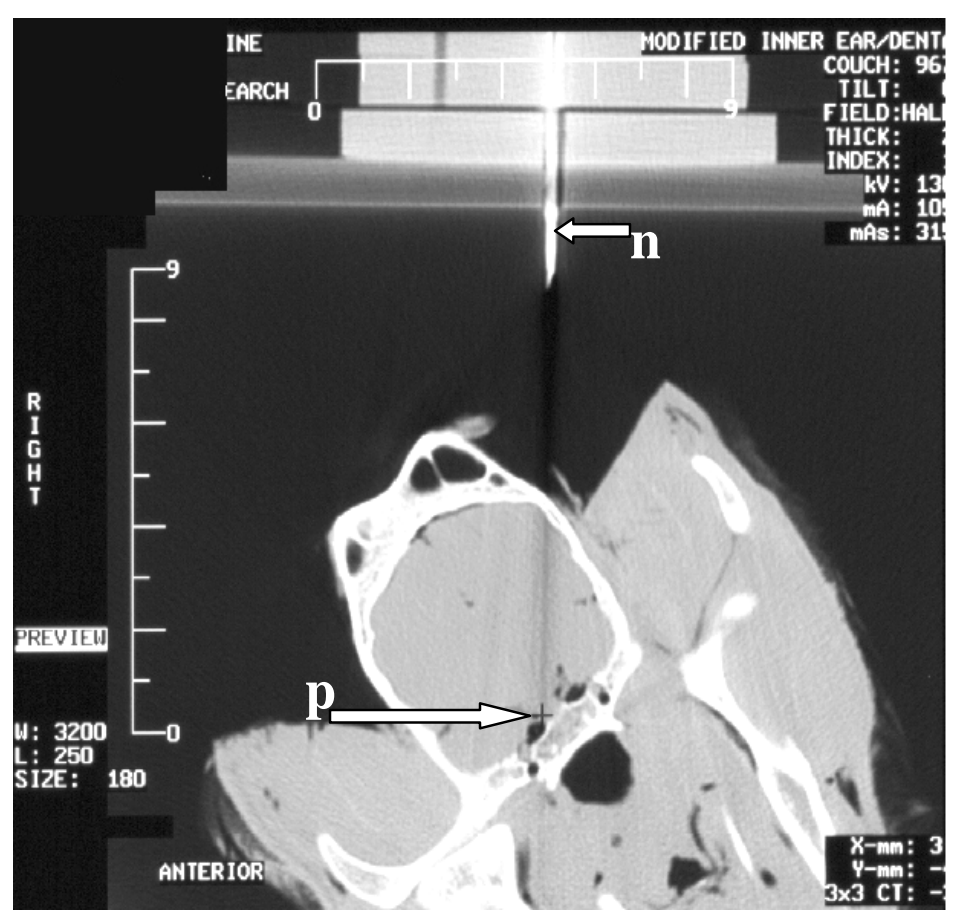

Figure 3-1. CT images demonstrating optimal angle of approach and pituitary target identification. The black cursor is in the right lobe of the pituitary gland (p). The needle (n) is in the needle fixture rig. The head has been rotated using the XYB-motion assembly and control system. 


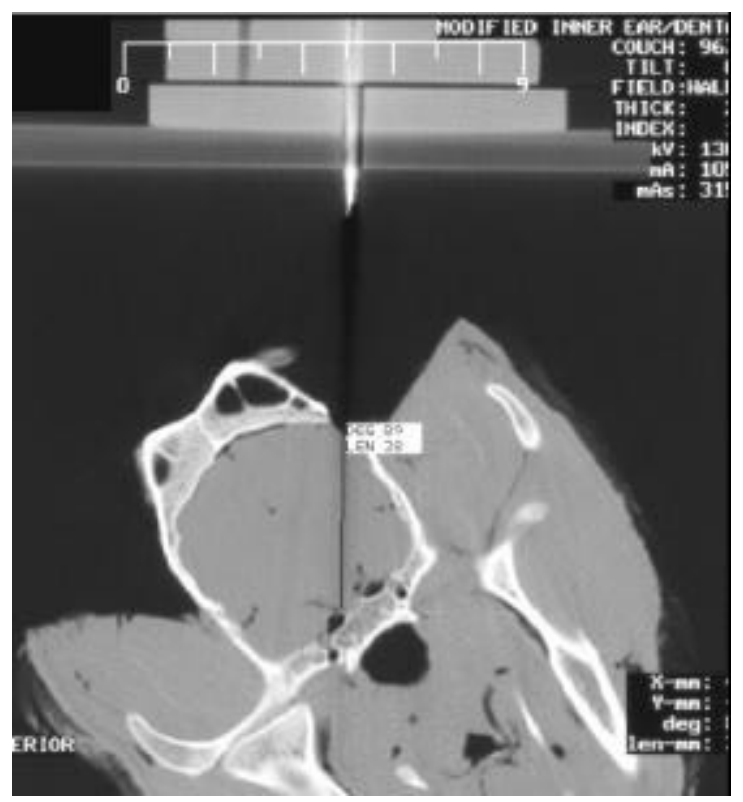

Figure 3-2. CT distance measurement before needle placement. The craniotomy is evident as a small defect in the left dorsal calvarium. The distance from the brain surface to pituitary target has been determined using the CT's computer software for distance measurements. LEN represents the distance measured; in this case $38 \mathrm{~mm}$. DEG indicates the angle of the needle trajectory ( 89 degrees).

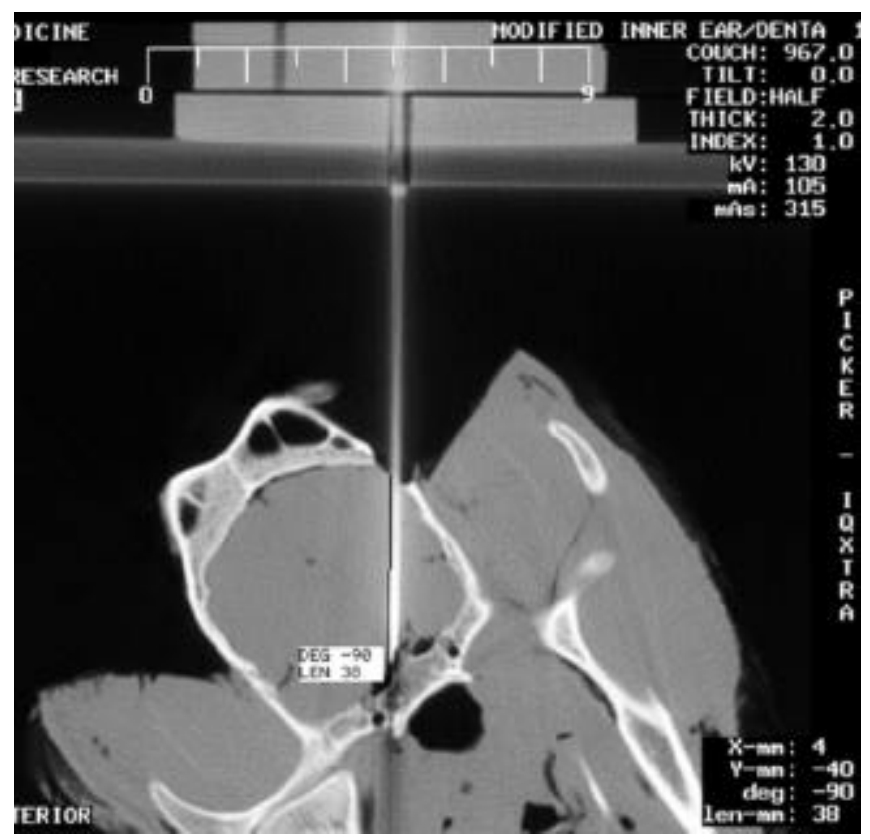

Figure 3-3. CT distance measurement after needle placement. The needle was advanced using CT guidance and distance measurements from brain surface to tip of the needle were recorded. 


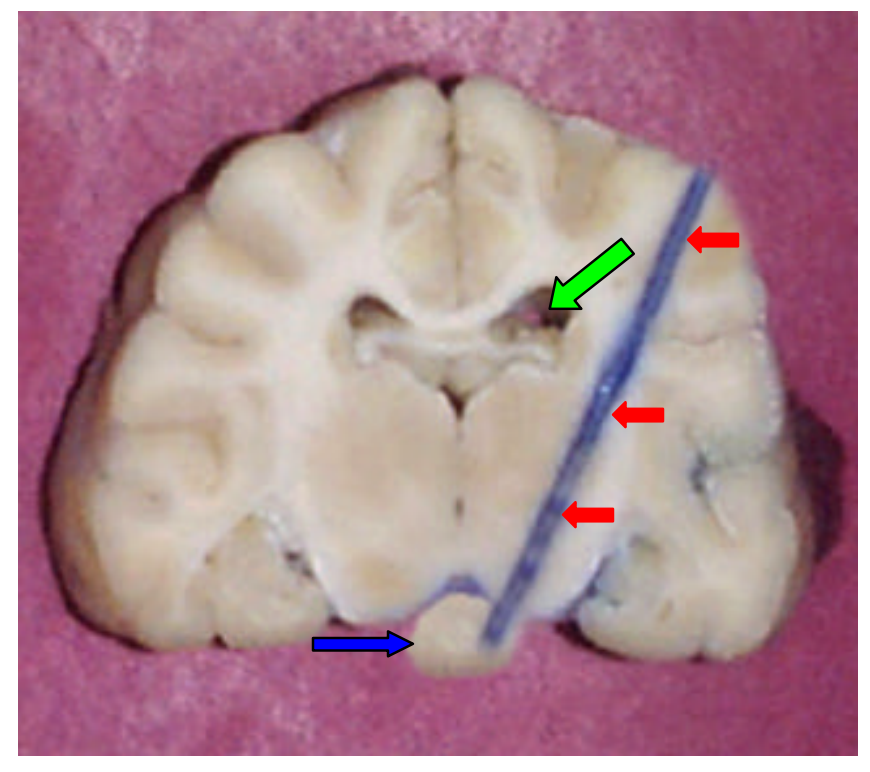

Figure 3-4. Actual needle track and confirmation of a successful pituitary (blue arrow) hit. The blue linear defect represents the previous needle track stained with tissue stain (red arrows). The length of the needle track was measured by two independent observers. Notice that the needle track also successfully avoided the lateral ventricle (green arrow).

\section{RESULTS}

The accuracy of the needle placement was defined as the proportion of hits of the target. The caudate nucleus and pituitary gland targets were hit 12 out of $16(75 \%)$ and 15.5 out of $16(96.8 \%)$ times, respectively. However, these 2 proportions were not statistically different $(\mathrm{p}<0.05)$. Actual and CT measurements for the pituitary and caudate nucleus targets are compared in figures 3-5 and 3-6. For both the pituitary gland and caudate nucleus, a significant difference $(\mathrm{p}<0.01)$ was identified for CT and actual track measurements. The CT measurements were greater than the actual, with a mean difference of 3.34 and $3.12 \mathrm{~mm}$ for the pituitary gland and caudate nucleus respectively. 


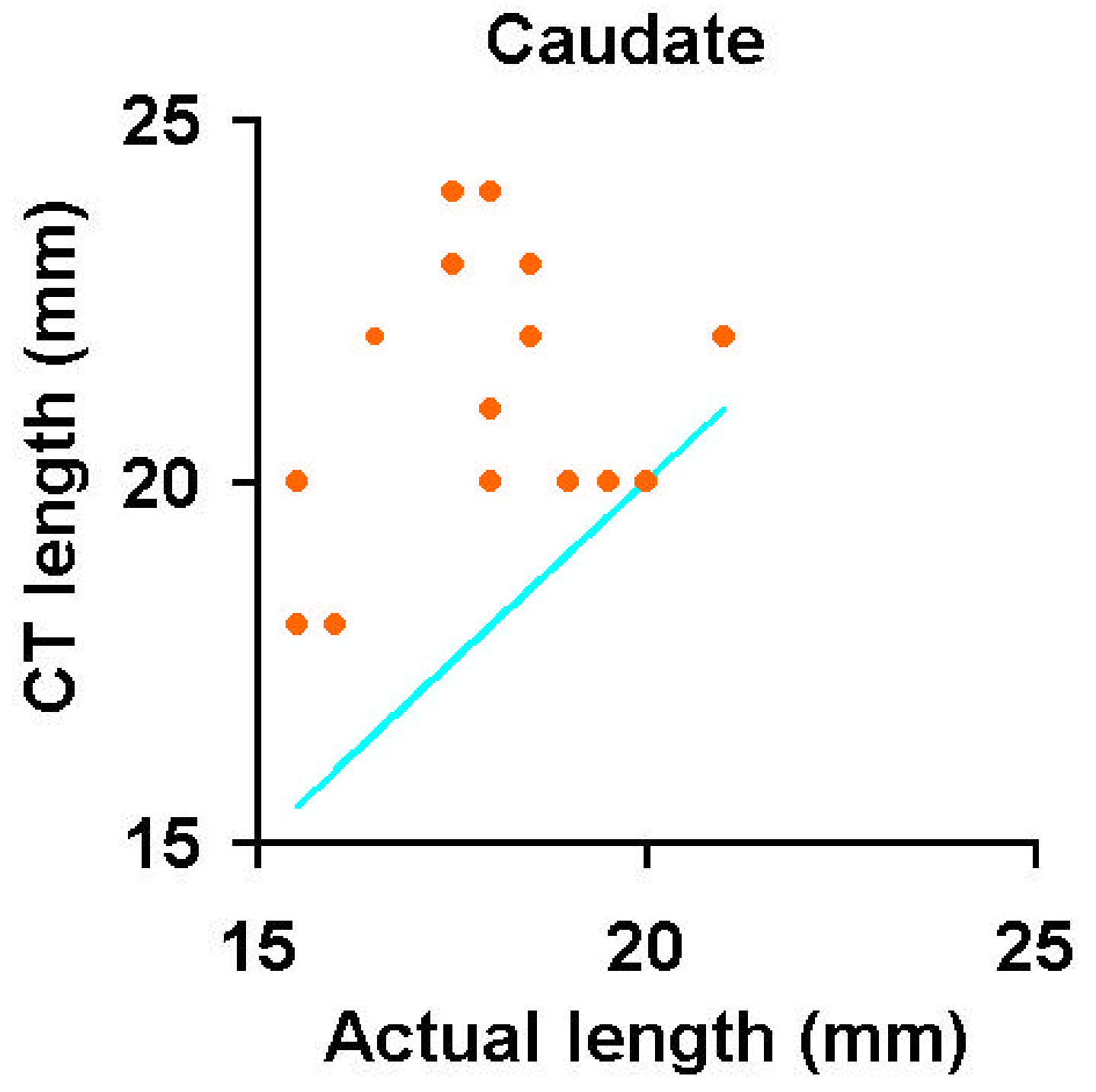

Figure 3-5. Comparison of CT length versus actual length of needle track for caudate nucleus target. The aqua line represents an ideal situation where the CT and actual length would be identical. Orange dots demonstrate measurements for each dog. Notice that CT lengths were consistently greater than actual lengths. 


\section{Pituitary}

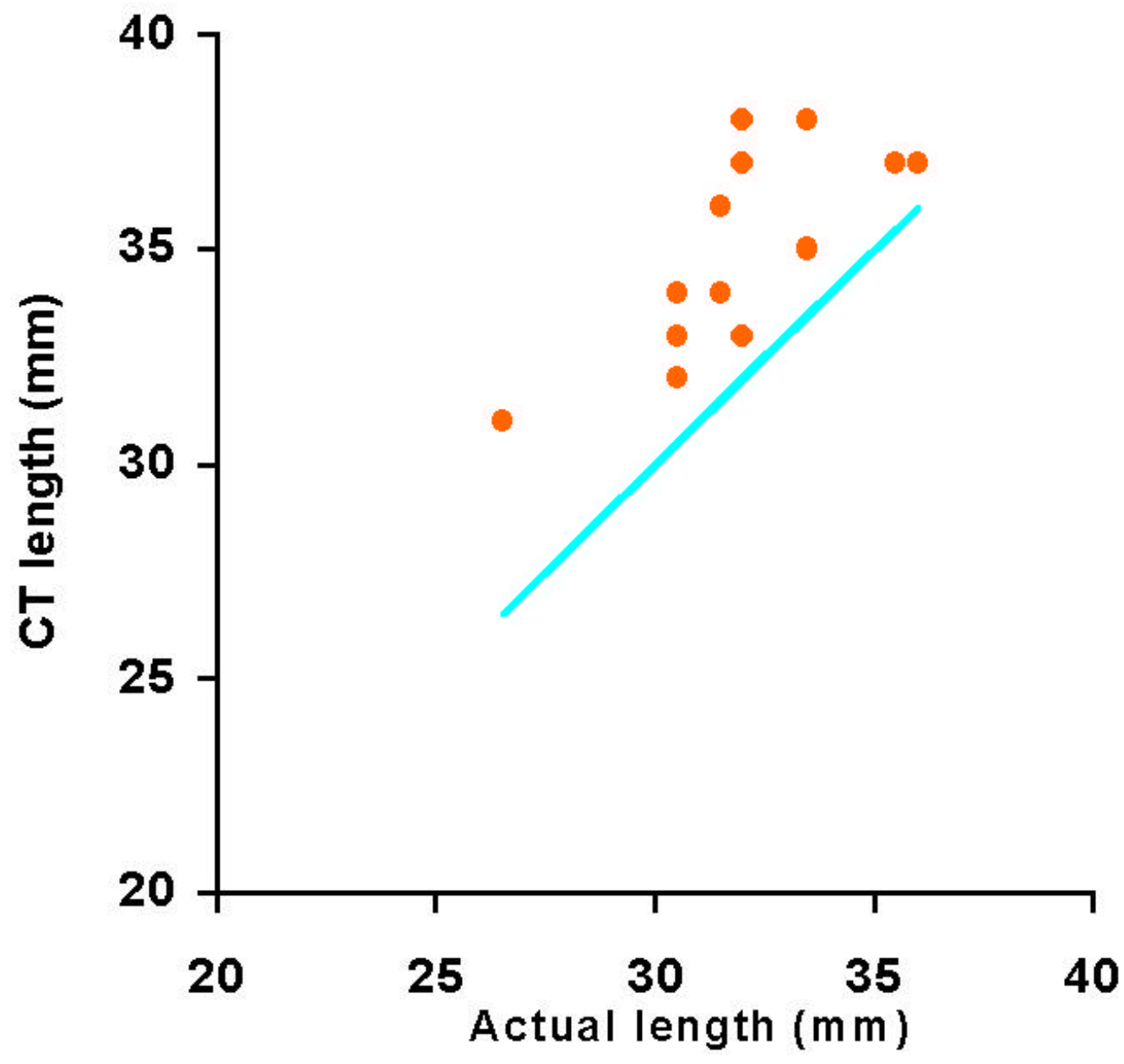

Figure 3-6. Comparison of CT length versus actual length of needle track for pituitary target. The aqua line represents an ideal situation where the CT and actual length would be identical. Orange dots demonstrate measurements for each dog. Notice that CT lengths were consistently greater than actual lengths. 


\section{$\underline{\text { DISCUSSION }}$}

The pituitary gland and caudate nucleus were chosen as targets because their location was believed to be easily recognizable on CT, they were of small size, and because they represented deep-seated brain targets. On transverse macroscopic sections, the head of the caudate nucleus has been reported to measure approximately $7 \mathrm{~mm}$ (dorsal to ventral borders) X $5 \mathrm{~mm}$ (1ateral ventricle to corona radiata). ${ }^{2}$ No reports describing the normal dimensions of the canine pituitary gland could be found. We measured pituitary size in 10 of our dogs to be an average of $7.5 \mathrm{~mm}$ in length, $6.5 \mathrm{~mm}$ in width and $4.0 \mathrm{~mm}$ in height.

Study results indicated that our new stereotactic device is equally accurate for needle placement into deep-seated and superficial brain targets. The pituitary had a fraction for the number of hits (15.5), because this number was an average obtained from two evaluators. Each evaluator respectively recorded a miss and a hit on the same target for one dog. In that case, there was a question whether or not if the needle tip reached the pituitary. This problem might have been prevented by measuring the distance from the needle fixture to the target, and estimating the needle length necessary to reach the target prior to needle placement. If the distance was too large, the needle fixture could have been relocated with the height adjustment.

The slightly lower number of hits for the caudate nucleus may have been due to the fact that the caudate nucleus was consistently more difficult to recognize on CT. Lateral ventricle visualization, which is critical for caudate nucleus location, was poor in some dogs. This might have been due to cerebrospinal fluid (CSF) loss during harvesting 
of the specimens. We attempted to minimize loss of CSF by occluding the vertebral canal with hand-kneadable epoxy putty. Also, we observed during brain slicing that we often placed our needle too far caudally. The caudate nucleus is larger more rostrally. If we had placed the needle more rostrally, we may have had more successful hits for the caudate nucleus.

In this experiment, the CT measurements of the needle track length were significantly greater than actual measurements. Because the brain specimens were preperfused with formaline, it is unlikely that fixation of the removed brain caused significant shrinkage. A CT computer error in distance measurement was also considered unlikely. A previous study comparing CT with actual distance measurements found CT to be highly accurate. 43 A more likely theory explaining the difference relates to the staining process and recognition of the needle track on the actual specimens. When the stain is injected into the needle track and then identified on slicing, the tip and bevel part of the needle might not stain completely. This would result in an apparent shortening of the needle track. To confirm this statement, we measured the length of the tip and bevel of the needle used for placement. This length measured $3.25 \mathrm{~mm}$, which correlates very well with the difference between the CT and actual needle track lengths. Measuring from the proximal end of the bevel, compared to the needle tip, might be better for comparing CT with actual needle track measurements.

For all the dogs, at the half-distance from each target, the needle had to be rotated 180 degrees. This was found in pilot studies to be necessary for adequate needle placement in the target. The needle tended to deviate from its planned track by going the 
opposite way of the bevel orientation. This problem may have been due to the decreased pliability of the brain tissue caused by the perfusion process. We chose to perfuse the brains because of time constraints and limited availability of the CT scanner. Also, perfusion reduced the likelihood of brain shrinkage during post-removal fixation. Needle deviation may be less likely in fresh brain tissue.

Our new device performed similarly for two different deep-seated targets. However, there was a tendency for the pituitary biopsy to be slightly more accurate. The fact that this device was created from a very small budget also shows promise as an alternative to more expensive medical devices currently available for CT-guided brain biopsy in dogs. The use of dental impression material and Plexiglas ${ }^{1}$ molds permitted rigid stabilization of the head without the need for invasive pins or screws. The needles were successfully placed using a single 5-mm craniotomy. Future studies are needed to improve the device and test biopsy collection accuracy in vivo.

\footnotetext{
${ }^{1}$ Rohm and Haas Company Corporation, Delaware Independence Mall, West Philadelphia, Pennsylvania.
} 


\section{THESIS CONCLUSIONS}

Results of our study present several important observations:

1) The canine head can be rigidly immobilized for brain biopsy without invasive components.

2) Computerized controls can be used to move the head for needle placement.

3) A CT-guided stereotactic device for dogs can be constructed for less than $\$ 1000$

4) Needle placement accuracy with this device is similar for both deep-seated brain targets.

We have successfully produced the first non-invasive CT-guided stereotactic device specifically made for the canine skull topography. This device employs no screws or burr holes, but only dental impression material, a molded Plexiglas maxillary support, and rubber padding. We also introduced the concept of integration of computer controls to move the head and help perform needle placements. The employment of computer controls to orient the head for needle placement has made possible the development of software that would integrate motion control and CT controls with the ultimate goal of entirely controlling the stereotactic brain biopsy procedure via the $\mathrm{CT}$ operator station. Producing this device for less than $\$ 1000$ illustrated the potential for less expensive stereotactic device construction and more availability for the veterinary market. To our knowledge, no previous study has compared CT-guided stereotactic needle placement accuracy for superficial and deep-seated brain targets. The performance evaluation of this 
device and the stereotactic procedure in vivo would be of benefit before clinical utilization. Additional studies are also needed to assess tissue sample quality using different biopsy needles. 


\section{BIBLIOGRAPHY}

1. Heymans Institute of Pharmacology UoGaMC, Department of Applied Linguistics Gent. Multilingual Glossary of technical and popular medical terms in nine European Languages, December 1995.

2. Thomas WB, Sorjonen DC, Hudson JA, et al. Ultrasound-guided brain biopsy in dogs. Am J Vet Res 1993;54:1942-1947.

3. Wen DY, Hall WA, Miller DA, et al. Targeted brain biopsy: a comparison of freehand computed tomography- guided and stereotactic techniques. Neurosurgery 1993;32:407-12; discussion 412-3.

4. Greenblatt SH, Rayport M, Savolaine ER, et al. Computed tomography-guided intracranial biopsy and cyst aspiration. Neurosurgery 1982;11:589-98.

5. Swaim SF, Vandevelde M, Faircloth JC. Evaluation of brain biopsy techniques in the dog. J Am Anim Hosp Assoc Sept Oct 1979;15:627-633.

6. LeCouteur RA. Brain tumors of dogs and cats: diagnosis and management. Veterinary medicine report. Fall 1990;2:332-342.

7. Meij BP. Transsphenoidal hypophysectomy for the treatment of pituitarydependent hyperadrenocorticism in dogs. Vet Q 1998;20 Suppl 1:S98-100.

8. Shores A, Braund KG, Stockham SL, et al. Diagnostic methods In: I. S. DH, ed. Textbook of small animal surgery. Philadelphia: W.B Saunders Co, 1985;12851308 .

9. Speciale J, Van Winkle TJ, Steinberg SA, et al. Computed tomography in the diagnosis of focal granulomatous meningoencephalitis: retrospective evaluation of three cases. J Am Anim Hosp Assoc July/Augl 1992;28:327-332.

10. Meij BP, Voorhout G, van den Ingh TS, et al. Results of transsphenoidal hypophysectomy in 52 dogs with pituitary-dependent hyperadrenocorticism. Vet Surg 1998;27:246-61.

11. Ostertag CB. Three_dimensional CT Scanning of the dog Brain. JComp Assit Tomog 1982;6:1036-1037. 
12. Maciunas R, Galloway R. Magnetic resonance and computed tomographic imagedirected stereotaxy for animal research. Sterotact Funct Neurosurg 1989;53:197201.

13. Harari J, Moore MM, Leathers CW, et al. Computed tomographic-guided, freehand needle biopsy of brain tumors in dogs. Prog Vet neurology. Summerm 1993;4:41-44.

14. Moissonnier P, Bordeau W, Devauchelle P, et al. CT-guided stereotaxic biopsy of intracranial lesions. Vet Surg 1998;vol:293.

15. Koblik PD, LeCouteur RA, Higgins RJ, et al. CT-guided brain biopsy using a modified Pelorus Mark III stereotactic system: experience with 50 dogs. Vet Radiol Ultrasound 1999;40:434-40.

16. Koblik PD, LeCouteur RA, Higgins RJ, et al. Modification and application of a Pelorus Mark III stereotactic system for CT-guided brain biopsy in 50 dogs. Vet Radiol Ultrasound 1999;40:424-33.

17. Bullard DE, Nashold BS, Osborne D, et al. Experience using two CT-guided stereotactic biopsy methods. Appl Neurophysiol 1983;46:188-92.

18. Hahn JF, Levy WJ, Weinstein MJ. Needle biopsy of intrancranial lesions guided by computerized tomography. Neurosurgery 1979;5:11-5.19. Moran CJ, Naidich TP, Gado MH, et al. Central nervous system lesions biopsied or treated by CT-guided needle placement. Radiology 1979;131:681-6.

20. James HE, Wells M, Alksne JF, et al. Needle biopsy under computerized tomographic control: a method for tissue diagnosis in intracranial lesions. Neurosurgery 1979;5:671-4.

21. Yeates A, Enzmann DR, Britt RH, et al. Simplified and accurate CT-guided needle biopsy of central nervous system lesions. J Neurosurg 1982;57:390-3.

22. Piskun WS, Stevens EA, LaMorgese JR, et al. A simplified method of CT assisted localization and biopsy of intracranial lesions. Surg Neurol 1979;11:413-7.

23. Maroon JC, Bank WO, Drayer BP, et al. Intracranial biopsy assisted by computerized tomography. J Neurosurg 1977;46:740-4. 
24. Leksell L, Jernberg B. Stereotaxis and tomography. A technical note. Acta Neurochirl 1980;52:1-7.

25. Roberts TS, Brown R. Technical and clinical aspects of CT-directed stereotaxis. Appl Neurophysiol 1980;43:170-1.

26. Mundinger F, Birg W. CT-stereotaxy in the clinical routine. Neurosurg Revl 1984;7:219-24.

27. Black P, Mechanic A, Markowitz R. CT-guided stereotaxic biopsy of brain tumors: new technology for an old problem. Am J Clin Oncoll 1987;10:285-8.

28. Mundinger F, Birg W. Stereotactic Biopsy of Intracranial Process. Acta Neurochirurgica 1984;33:171-181.

29. Apuzzo ML, Sabshin JK. Computed tomographic guidance stereotaxis in the management of intracranial mass lesions. Neurosurgery 1983;12:277-85.

30. Shahzad S, Rizwan M, Afaq S. Stereotactic Biopsy of Brain Tumours. J. Pak. Med. Assoc. 1996;46:176-178.

31. Goldstein S, Gumerlock MK, Neuwelt EA. Comparison of CT-guided and stereotaxic cranial diagnostic needle biopsies. J Neurosurg 1987;67:341-8.

32. Di Lorenzo N, Esposito V, Lunardi P, et al. A comparison of computerized tomography-guided stereotactic and ultrasound-guided techniques for brain biopsy [see comments]. J Neurosurg 1991;75:763-5.

33. Voges J, Schroder R, Treuer H, et al. CT-guided and computer assisted stereotactic biopsy. Technique, results, indications. Acta Neurochir 1993;125:142-9.

34. Duquesnel J, Turjman F, Hermier M, et al. CT-guided needle biopsy of intracranial tumours: results in 118 consecutive patients. Acta Neurochir Suppl (Wien) 1995;63:16-9.

35. Ostertag CB, Mennel HD, Kiessling M. Stereotactic biopsy of brain tumors. Surg Neurol 1980;14:275-83. 
36. Apuzzo ML, Chandrasoma PT, Cohen D, et al. Computed imaging stereotaxy: experience and perspective related to 500 procedures applied to brain masses. Neurosurgery 1987;20:930-7.

37. Greenblatt SH. Targeted brain biopsy: a comparison of freehand computed tomography- guided and stereotactic techniques [letter]. Neurosurgery 1993;33:536.

38. Horner NB, Potts DG. A comparison of CT-stereotaxic brain biopsy techniques. Invest Radiol 1984;19:367-73.

39. Krieger MD, Chandrasoma PT, Zee CS, et al. Role of stereotactic biopsy in the diagnosis and management of brain tumors. Semin Surg Oncol 1998;14:13-25.

40. Sawin PD, Hitchon PW, Follett KA, et al. Computed imaging-assisted stereotactic brain biopsy: a risk analysis of 225 consecutive cases. Surg Neurol 1998;4:640-9.

41. Greene CE, Braund KG. Diseases of the brain. In: e. Ettinger SJ, ed. Veterinary Internal Medicine. Philadelphia: WB Saunders Co, 1989;578-623.

42. Tidwell A, Johnson K. Computed tomography-guided percutaneous biopsy: criteria for accurate needle tip identification. Vet Radiol Ultrasound 1994;35:440444.

43. Jones JC, Wright JC, BARTELS JE. Computed tomographic morphometry of the lumbosacral spine of dogs. Am J Vet Res 1995;56:1125-32. 


\section{APPENDIX A}

\section{DETAILS OF PILOT STUDIES}

\section{Pilot study \#1}

\section{Materials and Methods}

An en bloc head and neck specimen was harvested from a junior surgery dog within 1 hour of euthanasia and frozen at 20-degrees Farenheight. Prior to CT scanning, the specimen was thawed for 24 hours in a refrigerator at a temperature of 34-36 degrees Farenheight. The specimen was dried with a towel and the distal part of the neck was covered with a plastic bag to minimize fluid leakage. The mouth was opened by exerting pressure on the mandible with a triangular wood block. The CT table fixation platform was attached using rubber-padded clamps. The maxillary portion of the head was placed in the head holding component and stabilized using a plastic mold, rubber pad, and tightening screws. A 12 gauge, 4 inch long, metallic hub, bone biopsy needle was placed in the needle fixture. The needle served as a reference for determining the gantry tilt needed for transverse CT scanning. Technique settings were: modified infant brain protocol, $2 \mathrm{~mm}$ slice thickness, $1 \mathrm{~mm}$ slice spacing, image size 256 , prone orientation, $130 \mathrm{kVp}, 20 \mathrm{ma}$, and 51 mas. The gantry tilt angle was incrementally adjusted to make the scan plane parallel to the plane of needle. The scan plane was determined to be parallel to the needle when we were able to visualize the entire length of the needle lumen from the hub to the bevel. The CT table position at the needle location was programmed as a zero value in the motion control system. The right caudate nucleus was identified after scanning a portion of the brain. Window and levels settings were adjusted as needed to maximize visualization of the target. The CT table position for the caudate nucleus relative to the needle was entered into the motion control system. The motion control system was then used to relocate the head such that the caudate nucleus was in the same scanning plane as the needle. The shortest distance from the brain surface to the target and the orientation (angle measured with the scanner utility) needed to execute the predetermined needle trajectory was measured. From these reference values, the head was rotated on its axis to accommodate the needle trajectory. Repeat scanning at the same CT table position helped determined the adequate head position for needle placement. No surgical approach was attempted due to time restriction. After removal of the specimen out of the head fixture, the brain was harvested from the skull and evaluated.

\section{Results and Conclusions}

The jaw of the specimen was very difficult to open due to rigor mortis. The CT-table fixation device was quick, easy and provided great stability. The head placement in the head holding fixture was not time consuming (approximately 5 minutes) and was totally stable. The needle created a large streak artifact, mainly originating from the large metallic hub. The scanning protocol initially used enhanced the needle artifact and produced a small image on the display. Use of a larger image size provided better visualization of the brain and stereotactic device. Calibration of the device was time consuming ( 60 to 75 minutes) and required seven different pilot acquisitions. The target identification was easier when brain window (170) and level (70) presets were used. The motion control system was inaccurate when the motor speed was set on fast. Attempts to use the initial coordinates in the motion control system (coordinate Z:0, $\mathrm{X}: 0, \mathrm{Y}: 0)$ did not consistently bring the head fisture in the exact same location. The repeated movement (between 4 to 8 tries) of the device required to center the target beneath the needle was time consuming. The angle needed to obtain the shortest brain surface-target distance (STD) exceeded 40 degree of head rotation. The needle angle measured with the CT scanner (56 degrees) was not the same as the head angle measured by the computerized motion system. The brain tissue was of a gelatinous consistency and did not maintain its shape after removal from the skull. 
Several conclusions were made from these results. First, the head and neck specimen should be stored with the mouth in an opened position. The CT table fixation device and the head holding fixture performed adequately. The needle should be replaced with one having a non-metallic hub to reduce the streak artifacts. The needle lumen and bevel should be used as a guide for gantry tilting and as a zero reference location for the CT table position. The modified infant brain CT scanning protocol worked well for guiding needle placement into the caudate nucleus. The motors in the motion control system should be used only at slow speed. The temporo-mandibular joint (TMJ) should initially be placed at the level of the needle in order to decrease the time required to relocate head such that the caudate nucleus is in the same plane as the needle. The CT angle measurement of the target relative to the brain surface can only be used as an approximation of the angle necessary to move the head with the motion control system. Maximum head rotation should be kept below 30 degrees to respect the natural cervical flexibility of a live animal. The specimen freezing technique was unsuccessful in maintaining sufficient brain tissue integrity for making actual depth measurements of the needle tract.

\section{Pilot study \#2}

\section{Materials and Methods}

Two head and neck specimens were harvested from dogs scheduled to be euthanized at the completion of other projects. Dogs were injected with a mixture of 1000 units / $\mathrm{kg}$ of heparin intravenously and sedated using $2 \mathrm{cc}$ of pentobarbital. Euthanasia was performed 10 minutes later using $6 \mathrm{cc}$ of pentobarbital. The dogs' head and neck specimens were harvested within 1 hour post-euthanasia. Both carotids were cannulated to permit pre-fixation of the brain tissue. First, 5 liters of non-sterile saline were infused to flush blood out of the specimen. A pump was used to maintain perfusion pressure at 3 pounds per square inch. The perfusion lasted about 15 minutes. A mouth gag was used to keep the jaw open during fixation. Then 7 liters of $10 \%$ formaline solution was infused over 20 minutes. The jugular veins, and vertebral and carotid arteries were clamped with hemostats during perfusion of the last liter of formaline. After perfusion, the specimens were placed in a container at room temperature for 90 minutes and then maintained until needed in a 34-36 degree Farenheight refrigerator. The brain from one specimen was removed and examined 24 hours after this technique to verify complete brain pre-fixation.

The second specimen was placed in the head holding fixture as described in the first pilot. A 14-gauge 6inch long jugular catheter was placed in the needle fixture. We used the modified infant brain scanning protocol as described in the pilot study \#1 conclusion. Before calibration, the head position in the device was adjusted with the motion controller to have the TMJ at the level of the needle position. The calibration was executed as reported in pilot study \#1 and the needle lumen and bevel were used to determine the zero reference CT table position. The left caudate nucleus was identified using a respective window and level setting of 896 and 72. The goal needle tract was drawn on the CT image with an electronic cursor, considering the rotation restriction of the head and the need to minimize involvement of the lateral ventricles. The STD distance along this tract was measured using the CT computer's distance software. The head was then moved into position using the motion control system set at a low speed. Repeat scans were performed as needed to place the left caudate nucleus in the same scanning plane as the needle. The coordinates on the motion controller were reset to zero when the optimal position was acquired. The needle was pushed to touch the skin and the skin was marked with a black permanent felt tip marker. The needle was retracted and the head was rotated back to a horizontal position. The CT computer was used to reposition the table such that the head and biopsy device were outside of the gantry. The needle fixture was removed. A skin punch biopsy was used to make an opening in the skin and the muscle covering the skull. A Michelle trephine (5 $\mathrm{mm}$ diameter) was used to make the skull opening. The CT table was moved back in the gantry at the original CT table position and the head was repositioned at the zero coordinates. A repeat CT scan was performed to confirm the optimal head position. The biopsy procedure on the left side was then stopped because of the misalignment of the skin and bone opening. The previous steps were repeated for the right caudate nucleus. The needle was introduced in the skull opening. Pre-placement STD 
was measured from the $\mathrm{CT}$ image using an electronic cursor. As the needle was gradually advanced, repeat CT scans were used to monitor needle placement.

When the catheter tip was seen to be within the left caudate nucleus, the post-placement STD was measured. The needle stylet was removed and $1 \mathrm{ml}$ of ethylene blue dye was injected. The catheter was removed. The brain was removed from the skull. The brain was sliced carefully, with a thickness of about $5 \mathrm{~mm}$. Slice orientation was adjusted as needed to match the plane of the biopsy needle tract. Actual STD measurement of the right needle tract was done.

\section{Results and Conclusions}

The perfusion/perfusion technique for specimen preparation was successful in maintaining the structural integrity of the brain tissue. The jugular catheter did not create unacceptable streak artifacts. However, the needle fixture was very unstable and permitted some movement of the needle during its introduction. The changes in the calibration and scanning protocols helped to diminish the time necessary to obtain adequate target position. The calibration was successfully performed in approximately 20 minutes. The head positioning for trajectory alignment required 8 to 12 attempts. The craniotomy procedure introduced several new problems to be overcome. The head holding fixture had too much flexibility during skull burring. It was difficult to apply sufficient pressure with the Michelle trephine. The skin and skull opening did not align accurately with the location wanted. When the needle was introduced into the left side, it hit the edge of the skin or the skull bone. For this reason head position adjustment and rescanning was repeated less than 5 times. Some fragments of bone were also seen at the surface of the brain. Following the left side procedure, the head got dislodged out of its position in the head holding fixture. The skin and skull openings on the right side were also malaligned and resulted in deviation of the needle as it was advanced. The final location of the needle bevel was within the left side of the right caudate nucleus, rather than the center as desired. Pre-placement STD measured $25 \mathrm{~mm}$. Post-placement STD was $22 \mathrm{~mm}$. The amount of ethylene blue injected was excessive, resulting in dissection of dye along the surface of the brain. Also, some lesions were created at the entry of the needle on the left side by the trephination. The brain was sliced with a brain knife and the right needle tract was easily identified and progressively isolated. The actual STD was measured to be $23 \mathrm{~mm}$. The CT needle tract measurement was therefore accurate to within $1 \mathrm{~mm}$ of the actual needle measurement.

Additional conclusions were made from these results. The perfusion technique was considered to be the best way to test the device and needle placement accuracy. To test histologic quality of the biopsy samples, fresh head specimens would be necessary. The needle fixture should be changed to improve stability of the needle. Additional support on the caudal portion of the maxilla would prevent dislodging of the head out of the device. Stronger components should be used to decrease the flexibility of the head fixture. A support device should be added under the head during trephination of the skull. To reduce the brain surface artifact from the trephine, the procedure would have to be done more carefully. A hypodermic needle would serve as a guide to keep orientation of the skin and skull opening aligned. The amount of ethylene blue filling the jugular catheter should be reduced to limit overflow and restrict the brain staining to its needle tract. The small difference between the STD on CT and actual STD might be from not correctly identifying the needle tip on CT. 


\section{Pilot study \#3}

\section{Materials and Methods}

The perfused /infused specimens were placed in the head holding fixture (with 2 half-inch thick rubber pads place to support the caudal maxillary dental arcades) and calibration followed. The same jugular catheter was introduced through a Teflon tube to improve the fit and to minimize the instability. The modified infant brain protocol was used as previously described. The left caudate nucleus was first identified as our target. During the skin and skull opening procedures, the head was supported ventrally with a large sandbag. Preplacement STD and needle angle measurements were obtained. After 6 adjustments, the needle was progressively introduced in the target with CT guidance. Postplacement STD was measured and ethylene blue was injected. The craniotomy procedure was repeated on the right side, with the goal of performing pituitary needle placement. The biopsy procedure had to be stopped before hitting the pituitary target because of a clinical case waiting for a CT scan. The brain was sliced and the biopsy needle tract was identified on the left side.

\section{Results and Conclusions}

The head remained in its fixture throughout the entire biopsy procedure. The needle fixture and rig, after small adjustments to fit the needle more precisely had satisfactory stability. Efforts to align the skin and bone opening more carefully were successful. Despite our efforts to avoid this, some bone fragments were still displaced into the brain tissue at the site of trephination. A small trephination artifact resulted in a focal indentation of the brain surface. Fewer trials (6 versus 8 to 12 in the second pilot) were needed to direct the needle in the opening but some adjustment still had to be made before introduction into the brain. The sandbag was helpful in supporting the head during the skull opening. The head holding fixture provided more stable support. During slicing of the brain, a part of the needle tract was cut off along the brain surface and the actual STD measurement could not be accurately provided. However the stained needle tract was seen to be within the central portion of the left caudate nucleus. The ethylene blue was mostly restricted to the needle tract.

Some conclusions were obtained from this pilot study. More care should be taken during brain slicing to not remove part of the needle tract. To reduce the brain surface artifact from the trephine, the procedure would have to be done more carefully. A fourth pilot was needed to evaluate our ability to biopsy the pituitary gland. This pilot should be performed on a weekend to avoid time constraints imposed by clinical cases.

\section{Pilot study \#4}

\section{Materials and Methods}

Additional head and neck specimens were prepared. One specimen was placed in the head holding fixture and calibration followed. The same jugular catheter was used as biopsy needle. An inner ear CT protocol was used, in an effort to improve visualization of the needle tip. This protocol has an edgeenhancement algorithm. Technique settings were: $130 \mathrm{kVp}, 315 \mathrm{mAs}, 2 \mathrm{~mm}$ slice thickness, $2 \mathrm{~mm}$ slice spacing. Calibration was performed as previously described and a left-sided approach to the pituitary gland was planned. Efforts were made to align the skin and bone opening carefully and to minimize brain surface damage by the trephine. Fewer trials were needed to direct the needle in the opening but some adjustment still had to be made before introduction into the brain. The needle was placed within the bone opening and preplacement STD was measured for the pituitary target. Then the needle was advanced with CT guidance. A final scan at that site confirmed the needle placement into the pituitary gland and postplacement STD 
was measured. The same procedure was performed from a right sided approach. The brain was sliced and the needle tracts were identified.

\section{Results and Conclusions}

The modified inner ear/dental improved slightly our ability to locate the tip of the needle. The bevel of the needle was better defined and it edged were sharper. The head did not remain in its fixture throughout the entire biopsy procedure. After the first trephination, while the head was placed back in position for needle introduction, the head moved and changed its position in the head fixture. During the replacement of the head in the fixture, the dorsal support broke and a second one was used with addition of sponges to increase skull apparatus contact.

A trephination lesion occurred at the left dorsolateral brain surface and was identified on CT. The postplacement STD for the left approach to the pituitary measured $31 \mathrm{~mm}$. A bone particle and trephination lesion also occurred at the right dorsolateral brain surface. The postplacement STD for the right approach was $38 \mathrm{~mm}$. This measurement was done from a surface of brain already indented by the trephination process. As the needle was advanced into the brain, the needle tip was angled out of the scanning plane. Identification of the needle tip occurred in a slice $2 \mathrm{~mm}$ rostral to the location of the remainder of the needle. The brain slicing was performed and approximate measurements only could be acquired from the right side because of the brain surface lesion. The end of the needle tract from the right side was successfully located in the pituitary gland. The end of the tract on the left side was difficult to determine because of excessive staining in that region. The actual right side STD was $42 \mathrm{~mm}$. The $4 \mathrm{~mm}$ discrepancy between the CT STD and the actual STD may have been caused by the needle angulation or by the lesion artifact at the brain surface.

From this last pilot we concluded that a different craniotomy technique might be helpful to decrease brain surface artifacts and improve STD measurement accuracy. To accomplish this task, skin and muscle flaps could be removed from each side and an air drill used to create the bone defect. This alternate craniotomy procedure would need to be tested in another head speciment before deciding whether to incorporate it into the final protocol. A larger gauge needle may be less likely to bend during advancement into the brain tissue, but might also be more likely to cause damage to the brain in a clinical situation. Some inaccuracy due to needle bending may therefore be unavoidable for deep-seated brain targets. A more stable head holding fixture will be needed. Orthodontic dental impression material should be used to prevent the head from rotating in the head-holding tray during the craniotomy procedure. The fit of the dorsal maxillary support should be tightened as needed with the use of gauze sponges. 


\section{APPENDIX B \\ LIST OF MATERIAS USED IN THE DESIGN}

\begin{tabular}{|c|c|c|c|c|c|}
\hline Components & $\begin{array}{c}\text { MATERIAL } \\
\text { SPECIFICATIONS }\end{array}$ & $\begin{array}{l}\mathbf{P A R} \\
\mathbf{T} \#\end{array}$ & $\begin{array}{c}\text { MANUFACTUR } \\
\text { ER }\end{array}$ & Comments & $\begin{array}{c}\text { Cost } \\
\$\end{array}$ \\
\hline $\begin{array}{l}\text { Horizontal plate of CT } \\
\text { table fixation device }\end{array}$ & 0.31 inch $(7.8 \mathrm{~mm})$-thick Plexiglas & & & & 55.00 \\
\hline \multirow[t]{2}{*}{$\begin{array}{l}\text { SFC of CT table } \\
\text { fixation device }\end{array}$} & $\begin{array}{l}\text {-metallic } 1 / 4(6.35 \mathrm{~mm})-2031 / 2 \text { inch }(88 \\
\mathrm{mm}) \text {-long mechanical hex cap screw }(1) \\
-1 / 4(6.35 \mathrm{~mm})-20 \text { tee nut fastener }(2)\end{array}$ & & $\begin{array}{l}\text { (1) and (2) Hillman, } \\
\text { Cincinnati, Ohio } 45321\end{array}$ & $\begin{array}{l}\text { The back SFC are } \\
\text { located on each side, } 15 \\
\text { inches from the back } \\
\text { edge. }\end{array}$ & $\begin{array}{l}2.00 \\
1.60\end{array}$ \\
\hline & $\begin{array}{l}\text { compressing Plexiglas paddle covered } \\
\text { with two } 0.25 \text { inch }(6.3 \mathrm{~mm}) \text {-thick } \\
\text { neoprene rubber pads }\end{array}$ & 9455 & $\begin{array}{l}\text { McMaster-Carr Company, } \\
\text { PO Box } 740100 \text { Atlanta, } \\
\text { GA } 30374\end{array}$ & $\begin{array}{l}\text { The compressing } \\
\text { Plexiglas paddle is } \\
\text { attached at the distal } \\
\text { extremity of the screw. }\end{array}$ & $\begin{array}{l}5.32 \\
12.00\end{array}$ \\
\hline $\begin{array}{l}\text { Horizontal plate of the } \\
\text { HHF }\end{array}$ & $0.375(9.5 \mathrm{~mm})$ inch-thick Plexiglas & & & $\begin{array}{l}\text { provides the main } \\
\text { weight support of the } \\
\text { head }\end{array}$ & 5.32 \\
\hline \multirow[t]{2}{*}{ HHF vertical support } & \#16 IPS Weld-on acrylic cement & W016 & $\begin{array}{l}\text { IPS Corporation, PO Box } \\
\text { 379, Gardena, CA } 90248\end{array}$ & $\begin{array}{l}\text { Fix Plexiglas vertical } \\
\text { support to the top } \\
\text { surface of the } \\
\text { horizontal plate }\end{array}$ & 4.74 \\
\hline & $\begin{array}{l}\text { three \#4-40 one inch }(25.4 \mathrm{~mm}) \text { long } \\
\text { mechanic stainless steel screws and } \\
\text { corresponding nuts }\end{array}$ & & $\begin{array}{l}\text { Curtis Industries, inc. } \\
\text { Eastlake, OH } 44095 \text { U.S.A }\end{array}$ & $\begin{array}{l}\text { Fix Plexiglas vertical } \\
\text { support to the top } \\
\text { surface of the } \\
\text { horizontal plate }\end{array}$ & 1.20 \\
\hline $\begin{array}{l}\text { Split bolt connectors of } \\
\text { HHF }\end{array}$ & $\begin{array}{l}21 / 4(6.35 \mathrm{~mm}) \text { inch long aluminum split } \\
\text { bolt } \\
\text { connectors }\end{array}$ & & $\begin{array}{l}{ }^{\mathrm{a}} \text { Series SBD, ILSCO } \\
\text { Corporation, } 4730 \\
\text { Madison Road, Cincinnati, } \\
\text { Ohio } 45227 \text { U.S.A. }\end{array}$ & $\begin{array}{l}\text { They are implanted in } \\
\text { the center of the } \\
\text { horizontal plate, to } \\
\text { accept the rotating rod }\end{array}$ & 6.58 \\
\hline
\end{tabular}




\begin{tabular}{|c|c|c|c|c|c|}
\hline Components & $\begin{array}{c}\text { MATERIAL } \\
\text { SPECIFICATIONS }\end{array}$ & $\begin{array}{l}\mathbf{P A R} \\
\mathbf{T} \#\end{array}$ & $\begin{array}{l}\text { MANUFACTU } \\
\text { RER }\end{array}$ & Comments & $\begin{array}{c}\text { Cost } \\
\$\end{array}$ \\
\hline Rotating rod of LMA & $\begin{array}{l}0.375 \text { inch }(9.5 \mathrm{~mm}) \text { wide by } 12 \text { inch }(30 \\
\mathrm{cm}) \text { long, zinc-plated rod }\end{array}$ & & $\begin{array}{l}\text { National MFG CO., } \\
\text { Sterling, IL } 61081\end{array}$ & $\begin{array}{l}\text { The back extremity of } \\
\text { the rod as a rectangular } \\
\text { shape to fit into the } \\
\text { lumen of the } 2 \text { large } \\
\text { split bolt connectors }\end{array}$ & 22.00 \\
\hline $\begin{array}{l}\text { Cylindrical vertical } \\
\text { Plexiglas components }\end{array}$ & $\begin{array}{l}9.1 \text { inches }(23.11 \mathrm{~cm}) \text { high by } 3 \text { inches } \\
(7.62 \mathrm{~cm}) \text { in diameter with a wide square } \\
\text { base }(3.3 \text { inches }(8.38 \mathrm{~cm}) \times 3.3 \text { inches }( \\
8.38 \mathrm{~cm})\end{array}$ & & & $\begin{array}{l}\text { Attach to the CT table } \\
\text { fixation device by } \\
\text { Nylon screws }\end{array}$ & 37.50 \\
\hline $\begin{array}{l}\text { Horizontal plate of the } \\
\text { needle stabilizer }\end{array}$ & $\begin{array}{l}\text {-two. } 25 \text { inch }(6.35 \mathrm{~mm}) \text { thick Plexiglas } \\
\text { rectangles } \\
\text {-Teflon }{ }^{\circledR} \text { tube of } 0.09 \mathrm{inch}(2.3 \mathrm{~mm}) \text { in } \\
\text { diameter }\end{array}$ & & $\begin{array}{l}\text { Teflon TFE Spaghetti, } \\
\text { McMaster-Carr } \\
\text { Company, PO Box } \\
740100 \text { Atlanta, GA } \\
30374\end{array}$ & $\begin{array}{l}\text { Plexiglas rectangles are } \\
\text { fixed on the main } \\
\text { Plexiglas horizontal } \\
\text { plate which has a } \\
\text { centered that contains } \\
\text { an inner Teflon tube } \\
\text { that accept the needle }\end{array}$ & $\begin{array}{l}5.32 \\
16.00\end{array}$ \\
\hline Transformer of MCS & 115/24 AC Volt 1 Amp transformer & 20070 & $\begin{array}{l}\text { MAXNC } 6730 \\
\text { W.Chicago St. Suites2 } \\
\& 3 \text {, Chandler, Arizona, } \\
85226\end{array}$ & $\begin{array}{l}\text { Supplies electrical } \\
\text { power to board }\end{array}$ & 18.09 \\
\hline $\mathrm{X}$ and $\mathrm{Y}$-axis of LMA & $\begin{array}{l}\text { - The slides are anodized aluminum of } \\
11.9 "(30.22 \mathrm{~cm}) \text { long x } 4 "(10.16 \mathrm{~cm}) \\
\text { wide x } 2.2 "(5.58 \mathrm{~cm}) \text { high. Their travel } \\
\text { distance is } 8 "(20.32 \mathrm{~cm}) . \\
-1 / 4(6.35 \mathrm{~mm})-2011 "(27.94 \mathrm{~cm}) \text { long } \\
\text { lead screw and screw nut and backlash } \\
\text { nut }\end{array}$ & $\begin{array}{l}20106 \\
179-416\end{array}$ & $\begin{array}{l}\text { MAXNC } 6730 \\
\text { W.Chicago St. Suites2 } \\
\& 3 \text {, Chandler, Arizona, } \\
85226\end{array}$ & $\begin{array}{l}\text { The lead screw is fixed } \\
\text { to each step motor and } \\
\text { articulates with the } \\
\text { linear slide by the } \\
\text { backlash nut. }\end{array}$ & $\begin{array}{l} \\
1.56 \\
12.00\end{array}$ \\
\hline
\end{tabular}




\begin{tabular}{|c|c|c|c|c|c|}
\hline Components & $\begin{array}{c}\text { MATERIAL } \\
\text { SPECIFICATIONS }\end{array}$ & $\begin{array}{c}\text { PART } \\
\#\end{array}$ & $\begin{array}{c}\text { MANUFACTU } \\
\text { RER }\end{array}$ & Comments & $\begin{array}{c}\text { Cost } \\
\$\end{array}$ \\
\hline $\begin{array}{l}\text { Cast iron-mounted } \\
\text { semi-precision bearings } \\
\text { system }\end{array}$ & $\begin{array}{l}\text { Supported by four } 1 / 4(6.35 \mathrm{~mm})-20 \\
\text { mechanical screws. } \\
\text { Inner diameter of } 3 / 8 \text { inch }(9.5 \mathrm{~mm})\end{array}$ & 668712 & $\begin{array}{l}\text { McMaster-Carr Supply } \\
\text { Company, P.O.Box } \\
\text { 740100, Atlanta, } \\
\text { Georgia, 30374. }\end{array}$ & $\begin{array}{l}\text { They support the } \\
\text { rotating rod and are } \\
\text { fixed on the top surface } \\
\text { of the } X \text { axis LMA, by } \\
\text { two sets of Plexiglas } \\
\text { holders. }\end{array}$ & $\begin{array}{l}1.60 \\
14.68\end{array}$ \\
\hline $\begin{array}{l}\text { Gearing system of Z- } \\
\text { axis }\end{array}$ & $\begin{array}{l}\text {-vertical 50/1 single thread gear worm } \\
-3 / 8 \text { inch }(9.5 \mathrm{~mm}) \text { inner diameter, } 50 / 1 \\
\text { single thread gear wheel }\end{array}$ & $\begin{array}{l}\text { DQ22C3 } \\
\text { DQ21F50 }\end{array}$ & $\begin{array}{l}\text { Allied Devices Corp., } \\
\text { 2365 Milburn ave, } \\
\text { Bladwin, NY,11510 }\end{array}$ & $\begin{array}{l}\text { The gear worm is } \\
\text { attached to the shaft of } \\
\text { the Z-axis motor } \\
\text { This gear wheel } \\
\text { articulates with single } \\
\text { thread gear worm fixed } \\
\text { on the stepping motor } \\
\text { shaft. }\end{array}$ & $\begin{array}{l}25.70 \\
33.29\end{array}$ \\
\hline $\begin{array}{l}\text { Computer station } \\
\text { Printer cable }\end{array}$ & $\begin{array}{l}\text {-Laptop computer } \\
25 \text { pin printer port cable }\end{array}$ & & $\begin{array}{l}\text {-Supersport Zenith } \\
\text { Laptop Data System }\end{array}$ & & $\begin{array}{l}20.00 \\
8.50\end{array}$ \\
\hline Electronic circuit board & $\begin{array}{l}\text { \#8 circuit board: rectifier, capacitor, } 10 \\
\text { ohm power resistors, } 1 \mathrm{k} \text { ohm resistors, } \\
500 \text { ohm resistor, } 2200 \text { ohm resistor, } 5 \mathrm{~V} \\
\text { voltage regulator, IC's, TIP power } \\
\text { transistors, block connectors, "D" male } \\
\text { connector, } 6 \text { pin connectors and cables. }\end{array}$ & 20120 & $\begin{array}{l}\text { MAXNC } 6730 \\
\text { W.Chicago St. Suites2 } \\
\text { \&3, Chandler, Arizona, } \\
85226\end{array}$ & & 255.00 \\
\hline
\end{tabular}




\section{APPENDIX C \\ DETAILED NEEDLE PLACEMENT PROCEDURE}

\section{A. Placement of the device on the CT table}

1. The CT table head support is first removed.

2. The CT table fixation device (containing the motion control system and NF) is placed on the front extremity of the CT table. The front edge of the CT horizontal plate is perfectly aligned with the front edge of the CT table.

3. The screwable fixing constituents (SFC) are then placed and held perpendicular to the long axis of the CT table. To apply compression, the mechanical hex screw of each screwable fixing constituent is rotated in a counter-clock fashion until tight.

4. Final verification of the position is done to assure perfect alignment.

5. The cables for each $\mathrm{X}, \mathrm{Y}, \mathrm{Z}$-axis motor are connected, and the computer is placed in front of the gantry.

6. Verification of the corrected axis of motor connection is performed with the software program, by moving individually each axis and motor in a fast mode (refer to computer and software startup). Changes are made if incorrect connection is present.

\section{B. Computer and software startup}

1. The computer and electronic board are turned on using their individual side switches.

2. The MS-DOS software loads-up and will give a $\mathrm{C}$ prompt.

3. To go to the MAXNC-PRO software, type: MAXNC, which will give the MAXNC directory.

4. Type MAX, which will open the program.

5. The program will demand to press the CAPSLOCK key.

6. Choose the axis by hitting the $\mathrm{X}, \mathrm{Y}$, or $\mathrm{Z}$ key and then from the menu, choose number 5 which is called "JOG". 
7. The speed of rotation is chosen by pressing the S key for slow and F key for fast; using the left or right SHIFT key, the motor is rotated (right SHIFT key makes motor rotate in a clock-wise fashion).

\section{Canine head placement}

1. Hardened maxillary dental impression material is positioned in the HHF by inserting, over the two front nylon screws, the perforated part of the dental impression material.

2. Then the canine mouth is kept as open as possible to fit the maxilla in its impression.

3. While holding the head in place, the maxillary support and a rubber pad are fitted over the top of the maxilla, nasal bone and sometimes frontal bone by inserting the four screws of the horizontal plate of the HHF.

4. Each corresponding nylon nut is placed and progressively tightened on it's screw. Careful attention must be paid to not over compress the maxilla because of high pressure applied on the maxillary support and danger of breakage.

5. At this time, each motion control system motor functioning is tested by rotating it in all directions on slow speed mode.

\section{Needle calibration}

1. Warm up CT scanner per instructions in operator manual.

2. A 14 gauge, 6-inch biopsy needle is placed in the needle fixture. The needle serves as a reference for determining the gantry tilt needed for transverse CT scanning.

3. The head is moved with the $X$-axis linear motion system so that the base of the ear canal is at the level of the needle.

4. Choosing from the program menu $\mathrm{X}$-axis and JOG, the HHF is moved progressively, in slow speed. 
5. Perform the first calibration scans

a. Touch head on the body icon on the ELTP.

b. Touch box for inner ear/dental protocol on the ELTP.

c. Touch proceed with new study on the ELTP.

d. Press Enter text key

e. Enter the information of the study.

f. Press F1 to save data.

g. Touch proceed to protocol parameters box on the ELTP. Change the following settings:

-Pilot scan horizontal

-Orientation head

-Orientation prone

h. Touch next protocol parameters screen box on the ELTP. Change the following settings:

-Image size 240

-Field size Half

-Couch index 1

-Thickness 2

i. Touch proceed to pre-scan on the ELTP

j. Touch select multiscan mode on the ELTP

-Change RPM Off.

-Press enter

k. Touch ready for scan on the ELTP and press Start button.

1. After acquiring the pilot, press F8 for plan of study. A plane of scanning is determined by localizing the NHA and needle on the CT monitor. The angle of the needle is determined by using the pilot study planning cursor, and placing it as parallel as possible with the needle orientation. Then, 4-6 slices are chosen at the needle level.

m. Press the F1 for first slice and F2 for last slice of the study. 
n. Press F8 to save plan of study.

o. Press Move couch and ready for scan on the ELTP

p. Set desired gantry angle on the gantry control panel

q. After the first slice acquisition, determine if re-centering is needed.

r. Press cursor op (F1) and center the cursor on the brain.

s. Press F6 for area ID

t. Press scan reprocess, then reprocess scan, and choose the slice number to reprocess on the ELTP.

u. Press Accept selection and proceed to prescan on the ELTP

v. Press ready to reprocess and ready for scan on the ELTP

6. After obtaining the slices of first scan, window and level settings are adjusted as needed to maximize visualization of the needle. Each scan slice is evaluated for parallelism with the needle. The entire needle lumen needs to be uniformly seen including its tip. The tip needs to have an abrupt end.

7. If this gantry angle is not adequate, additional pilot studies are performed using different gantry angles (+/- 0.5 degrees).

8. When the adequate gantry angle is determined, using the slice representing the best needle visualization, the $\mathrm{CT}$ table position (called reference couch position) is recorded and the table is move to that localization by choosing sequentially:
a. Change couch position
b. Enter the reference couch position
c. Move couch
d. Ready for scan
e. Press start button

9. When the CT table is positioned at the chosen needle location, the $\mathrm{X}, \mathrm{Y}, \mathrm{Z}$-axes are set as a zero value in the MAXNC-PRO program. To do that, following the initial 
software startup, the $\mathrm{X}$ key is typed to choose this $\mathrm{X}$-axis. From the menu, number 6 (zero axis) is chosen. This is repeated for each axis by typing their corresponding letter.

\section{E. Target identification}

1. The target is identified by scanning the brain. Window and levels settings are adjusted as needed to maximize visualization of the target.

a. For the caudate nucleus, starting scanning at the level of the caudal portion of the zygomatic arch appears to be helpful.

b. For the pituitary target, initial scanning was made at the level of mid-portion of the zygomatic arch.

2. When the ideal target slice location is determined, the CT table position is recorded. This position is subtracted from the reference position and the remaining number represents the length in $\mathrm{mm}$ that the head has to be moved to have the target aligned with the needle. If the number is positive, the HHF is move caudally using the X-axis and JOG key. To have the HHF move caudally, the left SHIFT key is chosen.

3. If the number obtained is negative, the head is move cranially and the opposite SHIFT key is used on the keyboard.

4. After relocation of the HHF, the head is scanned at the reference position to verify that the needle is centered over the target

5. The shortest distance from the brain surface to the target and the orientation (angle measured with the scanner utility) needed to execute the predetermined needle trajectory are measured using CT console cursor. The target console coordinates are recorded for the final measurement. An effort is made to avoid the ventricles. Maximum head rotation limit is 30 degrees.

6. From these reference values, the head is rotated with the Z-axis towards the desired side. To move the Z-axis in a counter-clock fashion the left SHIFT key is pressed.

7. When the angle chosen is obtained, another scan is performed at the reference position to evaluate head position. 
8. Repeat scanning at the reference position is done till adequate head position for needle placement is obtained (based on the predetermined needle trajectory).

9. When this position is acquired, the $\mathrm{X}, \mathrm{Y}, \mathrm{Z}$ axis are reset to zero.

\section{F. Craniotomy}

1. The needle is advanced to the skull and the location where the tip touches is marked with a sterile soft tip marker.

2. To perform the craniotomy, the needle is moved away from the skull. The CT table is positioned at couch position 500, and the head is rotated using the Z-axis motion so that the hard palate is parallel to the CT table.

3. The air tank valve is opened after the air drill system is assembled.

4. A $5 \mathrm{~mm}$ diameter round burr is used to create an approximately $5 \mathrm{~mm}$ craniotomy opening centered on the skull mark. Burring is stopped when the dura is reached.

\section{G. Needle placement}

1. The table is placed at the reference position.

2. Using the Z-axis control, the head is moved to the zero value.

3. The needle is advanced until the needle just touches the brain surface. The bevel is aligned so that the bevel is facing medially.

4. A scan is performed to confirm that the needle is centered correctly in the craniotomy opening.

5. Using the electronic cursor, distance is measured from the brain surface to the target.

6. Utilizing a precise metric caliper, the needle is marked with a fine tip pencil by placing the caliper on top surface of the NHA. Two marks are made: one at half the total distance and the second at the total distance.

7. The needle is advanced manually to the half distance mark. A scan is performed at the reference position to confirm the accurate progression of the needle through the brain.

8. Then, the needle is rotated 180 degree so that the hub is facing laterally. The needle is fully advanced to the second mark. 
9. A final reference position scan is acquired and the needle tip position is recorded to assure correct advancement to the target coordinates.

\section{H. Removal of the device}

1. The head is rotated using Z-axis motion so that the hard palate is parallel to the CT table.

2. The head is removed from the HHF by unscrewing, progressively and equally, the nuts holding the maxillary support in place.

3. To remove the device, the electronic board and computer are turned off, and the motor cables disconnected, and the screwable fixing constituents are loosened to permit removal of the CTTFA. 


\section{$\underline{\text { Vita }}$}

Alain Giroux is the first child of two, born on April 19 1972. His wonderful sister and he were raised in Canada in a French only speaking family. As a young boy, he always had the desire of building and inventing new things. At a very young age, when he stopped trying to swallow the Lego blocks, he spent most of his time constructing various things. At the age of 10 , he tried to build a small electronic helicopter, starting from scratch. He had a lot of imagination. He attended elementary, middle, high school and undergraduate college in Gatineau, Quebec, where most of his best friends live. Through high school, he was involved in several small science projects and fairs where he won multiple awards. After 2 years of undergraduate hard work and perseverance, he was accepted in the veterinary college of Montreal University, located in St.-Hyacynthe. There, he made great friends, obtained excellent references, and received the Senior Surgery Student of the year award, that permitted him to have an internship in a small animal private hospital in Ohio. He was, initially, afraid of moving to a different country where he would practice veterinary medicine for the first time and learn English. There, he found the love of his life, his wife, Jennifer. He also met great radiologists who helped him to be matched at Virginia Tech as their first radiology resident. After some research, Dr. Jones and he agreed that CT-guided stereotactic brain biopsy would be a challenging but exciting masters project. After graduation, Alain will be moving to the state of New York, to work in private practice as a radiologist and be closer to his family and friends. 